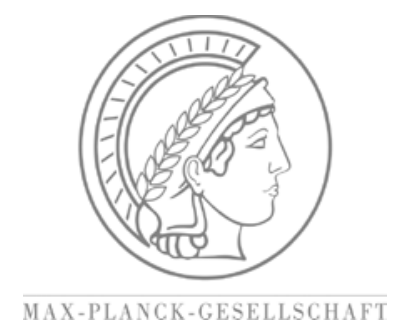

Explaining the (non-) causality between energy and economic growth in the U.S.

A multivariate sectoral analysis

by

\section{Christian Gross}

The Papers on Economics and Evolution are edited by the Evolutionary Economics Group, MPI Jena. For editorial correspondence, please contact: evopapers@econ.mpg.de

ISSN 1430-4716

(c) by the author
Max Planck Institute of Economics Evolutionary Economics Group Kahlaische Str. 10 07745 Jena, Germany Fax: ++49-3641-686868 


\title{
Explaining the (non-) causality between energy and economic growth in the U.S. - A multivariate sectoral analysis
}

\author{
Christian Gross \\ Max Planck Institute of Economics, Jena, Germany,gross@econ.mpg.de
}

\begin{abstract}
The rapidly growing literature on the relationship between energy consumption and economic growth has not univocally identified the 'real' causal relationship yet. We argue that bivariate models, which analyze the causality at the level of the total economy, are not appropriate - especially in cases where both variables do not cover the same scope of economic activity. After discussing appropriate pairs of variables, we investigate Granger causality between energy consumption and GDP in the U.S. for the period from 1970 to 2007 for three sectors - industry, commercial sector, transport as well as for the total economy. The choice of additional variables is based on major findings from the Environmental Kuznets curve literature and its critical reflections. Using the recently developed ARDL bounds testing approach by Pesaran and Shin (1999) and Pesaran et al. (2001), we find evidence for long-run Granger causality for the commercial sector, in case energy is the dependent variable, as well as bi-directional long-run Granger causality for the transport sector. We conclude that controlling for trade as well as increasing energy productivity significantly improves the fit of several extensions of the bivariate model.
\end{abstract}

Key words: energy, growth, multivariate ARDL, cointegration, granger causality JEL: Q4, C3

\section{Introduction}

What is the causal relationship between energy consumption and economic growth? It is the central question of the energy-growth nexus literature, which has been left unanswered univocally - after more than three decades of empirical research. The first empirical studies were stimulated by the energy crises of the 1970s (Kraft and Kraft, 1978; Akarca and Long, 1980). More recently, interest in the causality question has gained new momentum with concerns about climate change with following proposals to limit $\mathrm{CO}_{2}$ emissions by restricting fossil fuel consumption, with concerns about Peak Oil, and finally with the development of new analytical techniques. It has been discussed that conflicting results may arise due to different time periods of the studies, countries' characteristics, variables used, and different econometric methodologies see Ozturk (2010) and Payne (2010) for an overview.

Another, even more important reason for why the evidence is so weak is the level of aggregation. To our knowledge, the bivariate study by Zachariadis (2007) is the only study which analyzed the relationship between sectoral energy consumption and sectoral GDP. Other studies focused either on sectoral energy consumption and total GDP (e.g. Bowden and Payne, 2009) or total energy consumption and sectoral GDP (e.g. Yu and Jin, 1992; Thoma, 2004). For the U.S. Zachariadis could not find evidence for Granger causality at the level of the total economy, but he found evidence for short-run Granger causality at the sectoral level. In statistical analyses, it is not uncommon that evidence can be found at a lower level aggregation, although the results for the total population suggests the opposite. This phenomenon has been named 'Simpson's Paradox' 
after E. Simpson $(1951)^{1}$. However, if the results for Granger causality tests are found to be dependent on the level of aggregation and not on the variables, it is necessary to analyze the causal relationship at the 'correct' level of aggregation. Otherwise, the results are spurious and policy advice should be given with caution. The paradox becomes even more severe if the pair of variables for Granger causality analyses are not matching ${ }^{2}$. For this reason, we will extend Zachariadis' notion of appropriate pairs for causality analyses.

The fact that sectors differ with respect to their relationship between energy and growth, is well known in the environmental Kuznets curve (EKC) literature: changes of the industry composition have a changing impact on the energy demands of the economy over time. In the early phases of modern economic growth, when a country industrializes, structural change is believed to increase these demands. Later on when the country enters the post-industrial phase, or the service economy, the energy demands are believed to decline (e.g. Kahn, 1979; Panayotou, 1993; Panayotou et al., 2000; Smil, 2000; Schäfer, 2005). However, Henriques and Kander (2010) show that parts of the decline can be explained by misspecified price indices. The resulting divergence between energy and economic growth is also a challenge for Granger causality analyses. In order to account for the increasing energy productivity in a Granger causality framework, we suggest to include major findings from the EKC literature: one major finding is the role of the increasing energy productivity, which leads to the divergence between energy and growth. Another main finding is the role of trade, especially for goods producing industries, where energy intensive production has been offshored according to the Pollution Haven Hypothesis (PHH).

For our analysis we use the recently developed autoregressive distributed lag (ARDL) bounds testing approach as proposed by Pesaran and Shin (1999) and Pesaran et al. (2001). We analyze the evidence for long-run as well as short-run Granger causality between final energy consumption and GDP for the U.S. from 1970 to 2007 for the total economy, as well as for the industry sector, the commercial sector, and the transport sector. After identifying appropriate pairs of variables for the Granger causality analysis, we test bivariate as well as multivariate specifications of the model in order to avoid omitted variable bias. The choice of additional control variables is based on major findings of the EKC literature and its critical reflections. We find evidence for longrun Granger causality in the commercial sector when energy is the dependent variable. We also find evidence for bi-directional Granger causality in the transport sector. Adding or removing additional control variables is found to establish or break long-run Granger causality relationships. This finding is important especially in the transport sector, where the consideration of increasing energy productivity neutralizes the long-run relationship between energy and economic growth when output is the dependent variable. For the industry sector we find that controlling for trade is important for identifying short-run Granger causality when output is the dependent variable. We conclude that some of the divergence across sectors can be explained by the fundamental differences between goods and service producing industries. In various specifications energy productivity is found to Granger cause output as well as energy. The latter is interpreted as evidence for 'Jevon's Paradox' ${ }^{3}$. We find only weak evidence for the impact of energy prices on energy consumption in the transport sector. Given the evidence of long-run Granger causality at the sectoral level, compared to the non-existence at the level of the total economy, we conclude that the Granger

\footnotetext{
1 "A number of situations in which statistical dependencies that are consistent in subpopulations disappear or are reversed in whole populations have come to be referred to as Simpson's paradox" (see Hoover, 2008, p. 19).

${ }^{2}$ This is the case if, for example, fuel consumption and total / sectoral GDP is selected as a pair for a causality analysis. The results do then strongly differ between the sectoral level and the total economy, because fuel is used overproportionally (relative to the total economy) in the transport sector but underproportionally in the commercial sector.

${ }^{3}$ Jevons (1864) maintained that technological efficiency gains - specifically the more "economical" use of coal in engines doing mechanical work - actually increased the overall consumption of coal, iron, and other resources, rather than "saving" them, as many claimed. Twentieth-century economic growth theory also sees technological change as the main cause of increased production and consumption ('rebound effect'; see also Alcott, 2005).
} 
causality between energy and growth should only be analyzed at the sectoral level. Otherwise, results for the total economy are spurious.

The paper is organized as follows: first, we discuss the mixed evidence for Granger causality in the existing empirical literature. We further elaborate Zachariadis' (2007) identification of appropriate pairs for causality analyses and use those pairs we regard as appropriate for the empirical analysis. We also discuss our extensions of the basic bivariate models often used in the empirical literature. Section 3 describes the econometric methodology. We investigate the causal relationship between energy consumption and economic growth in the U.S. for the period 19702007 and three economic sectors as well as for the total economy. Cointegration tests are based on the ARDL bounds testing procedure as proposed by Pesaran and Shin (1999) and Pesaran et al. (2001). Afterward, we analyze the existence of long-run and short-run Granger causality. In Section 4 we discuss our findings and the final section concludes.

\section{The (non-) causality between energy and GDP: mixed evidence and omitted vari- able bias}

Ecological economists describe the economy as a subsystem of the entire ecosystem, which depends on natural resource flows - especially energy (e.g. Schurr et al., 1960; Ayres and Warr, 2009). In this environment, economic production is considered a "process of upgrading matter into highly ordered [...] structures, both physical structures and information" (Cleveland et al., 1984, p. 892). This upgrading is only possible with the use of energy. Consequently, ecological economists regard energy also as a crucial driver of economic growth. Stern (2011), for example, explains the tremendous economic growth since the industrial revolution by the switch of energy scarcity to energy abundance. Given the important role which theory assigns to the relation between energy and economic growth, we should be able to observe a causal relationship or at least some correlation between energy consumption and economic growth from historical data. However, the empirical evidence from the energy-growth literature is rather mixed and weak.

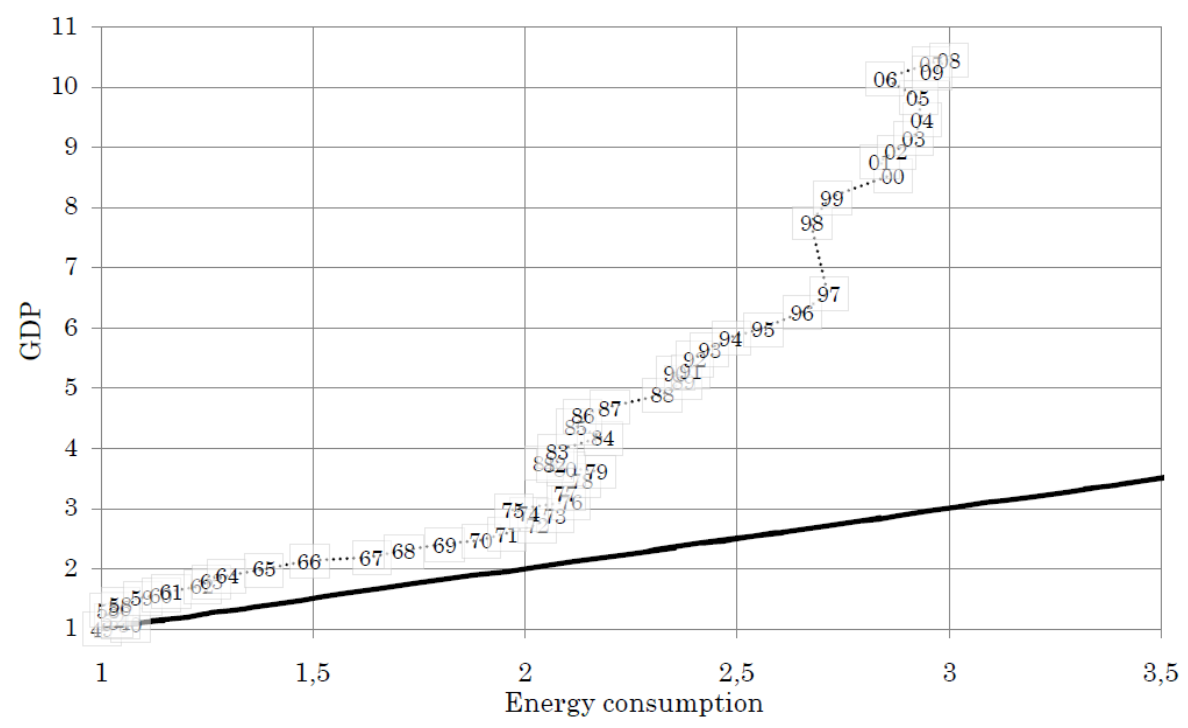

Fig. 1: Development of GDP and energy consumption in the U.S., 1949-2009 $(1949=1)$; solid line represents constant energy efficiency.

Fig. 1 shows the development of GDP in constant prices as a function of energy consumption in British thermal units (Btu) from 1949 to 2009. Until the late 1970s the relationship is almost 
linear. After the oil crisis in the late 1970s there is a drop-back of energy consumption, while GDP remains almost constant. At the beginning of the 1980s, the slope is continuously increasing with another drop-back in the late 1990s. The figure indicates that studies covering this early period should be more likely to find evidence for a relationship between energy consumption and growth, while later studies have to deal with the increasing energy efficiency. In the EKC literature, the increasing energy efficiency at the level of the total economy is also known as the de-coupling between energy and economic growth. As the theory of the EKC assumes that the development of energy-related parameters is invertedly U-shaped with respect to increasing income per capita, it describes a non-linear relationship between income and energy-related parameters.

A shortcoming of the energy-growth literature is the underlying assumption of the same relationship between energy and economic growth over time. Causality is either running from energy to growth ('growth'), from growth to energy ('conservation'), is bi-directional ('feedback') or absent ('neutrality'). An obvious solution to account for the, in fact, nonmonotonic development of the energy-growth relation is to control for (several) structural breaks. However, recent empirical results show that the reason for the divergence is more fundamental and should be elaborated in more detail. In a multi-sectoral bivariate analysis, Zachariadis (2007) found no evidence for short-run Granger causality at the level of the total economy, but for the commercial as well as for the transport sector. Fig. A.4.1-A.4.3 indicate why the results differ across the three sectors - industry, commercial, as well as transport ${ }^{4}$ — and why the results for the total economy are poorly related to the evidence at the sectoral level. The figures show the same plot as in Fig. 1, but with the development of sectoral value added relative to the development of sectoral energy consumption. We find an increasing energy efficiency in all sectors. However, the scales differ so that the increase in energy efficiency is sector-specific. We will later argue that the increasing energy productivity of the capital stock explains large parts of the divergence. In the industry sector, in addition, we find an almost arbritary development of energy and value added, which makes an in-depth investigation necessary. We assume that the separability of the value added chain of goods producing industries explains parts of the divergence. However, before the discussion of the sector-specific developments, we review the energy-growth literature, which has been published for the U.S ${ }^{5}$. We suggest that the identification of (in-) appropriate pairs of variables helps to better integrate the various approaches and results form the energy-growth literature.

\subsection{Appropriate (pairs of) variables for causality analyses}

In the energy-growth literature we find a consensus rather in methodological terms than with respect to the choice of similar pairs of variables. Zachariadis (2007) suggests "to select appropriate pairs of energy and economic variables (and the corresponding additional variables in multivariate models) in order to ensure that causality test results will be meaningful. In this respect one can observe in several causality studies that the pairs of variables are not matching. [...] Since the energy and economy variables in such cases do not cover the same area of economic activity or are sometimes expressed in different units [...], it is questionable whether profound policy implications can be deduced from their results" (Zachariadis, 2007, p. 1238). Accordingly, the results from different studies are ambiguous only at first sight given that they are based on various combinations of different variables. Disaggregating the studies with respect to the parameters used for causality analyses clarifies that results inevitably differ among the studies. In the light of the numerous combinations of pairs of variables, we select the most common pair as a reference model, namely total (final) energy consumption (measured in thermal equivalents) and total GDP in constant

\footnotetext{
${ }^{4}$ The dataset provided by the Bureau of Economic Analysis (BEA) reports agriculture as a part of manufacturing, see Section 3.1 for details.

${ }^{5}$ The majority of energy-growth analyses has been published for the U.S. For reasons of compatibility and data availability, we also limit our empirical analysis to the U.S.
} 
prices $^{6}$. This pair has been adapted in the studies by Kraft and Kraft (1978), Akarca and Long (1980), Abosedra and Baghestani (1991), Yu and Hwang (1984), Yu and Choi (1985), Cheng (1995), Zarnikau (1996), Soytas and Sari (2003), Soytas et al. (2007), and Chiou-Wei et al. (2008) (see also Table A.1 in the Appendix). None of these studies using GDP as a measure for output finds evidence for long-run Granger causality in either direction ${ }^{7}$.

\subsubsection{Total energy consumption or consumption of single resources?}

Instead of total energy consumption, another branch of the empirical literature selects single (groups of) energy sources together with total GDP as a pair for causality analyses. Sari et al. (2008) use single energy sources, Murry and Nan (1994) as well as Narayan and Prasad (2008) use electricity, Thoma (2004) uses (sectoral) electricity consumption together with an industry production index, Bowden and Payne (2009) use (sectoral) primary energy consumption, and Payne (2009) as well as Payne and Taylor (2010) use (non-) renewable energy. If different energy aggregates are used across studies, the results naturally differ by comparison. Instead of analyzing the results in detail, we briefly discuss how the development of single energy sources matches with the development of total GDP.

Fig. A.1 and Fig. A.2 show the development of energy consumption of different energy sources as well as the development of market shares of different energy sources. From 1949 to 2009 total GDP multiplied by a factor of 7 (Fig. A.1). While natural gas, renewables, as well as petrol grow moderately by a factor of 4 , electricity grew by a factor of 12 . The consumption of coal dropped almost to zero. At first sight, the high increase of electricity consumption suggests that electricity is an important 'partner' variable for a causality analysis with total GDP. But is the consumption of electricity also a relevant determinant in terms of its share in total energy consumption? Fig. A.2 shows the share of each energy source in total energy consumption. It is evident that energy consumption is dominated by the consumption of petrol and natural gas. The quantitative share of coal went down from about $37 \%$ and is almost negligible today. Although Fig. A.1 suggested that the consumption of electricity as well as the consumption of renewable energy carriers is continuously growing, both variables are almost negligible with respect to their market shares. In such cases, one should be aware that a causality analysis with, e.g., electricity consumption as a 'partner' variable, accounts only for $10 \%$ of total energy consumption.

Moreover, Marchetti (1977) showed that energy sources are subject to substitution over time. In a causality analysis framework the selection of single energy sources then inevitably leads to a distortion of the results: the increase or decrease of a single resource is not necessarily related to economic growth, especially if an emerging gap in energy supply is filled by another resource.

Bowden and Payne (2009) use primary energy consumption instead of final energy consumption, which excludes the consumption of (secondary) electricity ${ }^{8}$. As the consumption of electricity, however, was one of the main drivers of the increase of total (final) energy consumption, there is reason to be skeptical about the appropriateness of choosing primary energy consumption and total GDP as a pair of variables. Accordingly, we assume that only the sum of all energy sources is an appropriate variable for an energy-growth causality analysis.

\footnotetext{
${ }^{6}$ Note that, before 1991, GNP was the primary measure of output in the U.S. As GNP defines its scope according to ownership (not location), there is a mismatch with the energy statistics, because the official measure of energy consumption accounts only for energy consumed within the borders in the U.S. Accordingly, GNP (but not GDP) can change without necessarily affecting the amount of energy consumption and vice versa (see also OTA, 1990).

${ }^{7}$ Kraft and Kraft (1978), Akarca and Long (1980), and Abosedra and Baghestani (1991) use GNP instead of GDP. Moreover, Akarka and Long conclude that the results found by Kraft and Kraft sensitively depend on the time period. Zarnikau (1996) analyzes 'instantaneous Granger causality' (see Section 3.4). Finally, Stern (1993) chooses primary (which excludes electricity) instead of final energy consumption.

${ }^{8}$ Primary energy denotes energy embodied in natural resources whereas secondary energy comes from the transformation of primary or secondary energy (see OECD/IEA/Eurostat, Energy Statistics Manual, Paris, 2005).
} 


\subsubsection{Total GDP or other output indices?}

Several empirical studies use GDP per capita (Soytas and Sari, 2006; Chontanawat et al., 2006, 2008) or an industry production index (Yu and Jin, 1992; Thoma, 2004; Sari et al., 2008) instead of total GDP. Fig. A.3 shows the development of GDP, GDP per capita, industry value added ${ }^{9}$, and total energy consumption. It shows an increasing gap between GDP and total energy consumption, while the development of the industry production index and GDP per capita is much closer to total energy consumption. However, GDP per capita as well as the industry production index do not cover the same scope of economic activity. While total energy consumption covers, in sum, four sectors (residential, industry, transport, and commerce), the industry production index of output accounts only for about $30 \%$ of economic activity. Accordingly, the results found for the industry production index as well as per capita GDP, are very specific and should not be mixed with the results found for total GDP ${ }^{10}$. Therefore, if total energy consumption is used as variable in a causality analysis, we assume that only total GDP covers the same scope of economic activity and should be preferred for a variable pair.

\subsubsection{Thermal equivalents or energy quality indices?}

Instead of thermal equivalents, a number of studies (Stern, 1993; Zarnikau, 1996; Stern, 2000) use a discrete approximation of the Divisia index as suggested by Berndt (1978). Warr and Ayres (2010) use exergy instead of energy, which has been proposed by Ayres and Martinas (1995) and Ayres et al. (1996).

The simplest form of aggregation is to add up the individual variables according to their thermal equivalents. The thermal equivalent approach is advantageous because it uses a simple and welldefined accounting system based on the conservation of energy and the fact that thermal equivalents are easily and uncontroversially measured. Most methods of energy aggregation in economics and ecology are based on this approach (see Cleveland et al., 2000).

Schurr et al. (1960) emphasize the economic importance of energy quality. They argue that weighting energy use for changes in the composition of energy input is important because a large part of the growth effects of energy are due to substitution of higher quality energy sources such as electricity for lower quality energy sources such as coal. It is generally believed that electricity is the highest quality type of energy followed by natural gas, oil, coal, and wood and biofuels in descending order of quality. This is reflected by the typical prices of these fuels per unit of energy. The discrete approximation to the Divisia index, as suggested by Berndt (1978), is based on the idea that the price paid for a certain unit of an energy source is a proxy for its quality ${ }^{11}$. The problem is that the weight of each energy source critically depends on the 'correct' price, which may not correctly reflect the marginal product of each energy source (Kaufmann, 1994). Hong $(1983)$ and Zarnikau $(1996 ; 1999)$ demonstrated that the application of the Divisia index and thermal equivalents leads to different conclusions regarding trends in energy-output ratios for the U.S. economy. Divisia energy indices for U.S. industrial and residential energy consumption have grown much faster than heating value energy aggregates. This divergence is the result of an increasing electrification and price-related factors.

The results from the exergy approach used in the empirical study by Warr and Ayres (2010) lack in compatibility. So far, this approach has not been applied in other studies, particularly due to the high complexity of calculation. In this study we use the aggregation of energy sources according to their thermal equivalents. We also share Kaufmann's skepticism about prices being a good proxy for the economic usefulness of energy sources as discussed above.

\footnotetext{
${ }^{9}$ Here, we use the industry value added as a proxy for the industry production index

${ }^{10} \mathrm{GDP}$ per capita is usually considered a measure for the standard of living or the stage of development.

${ }^{11}$ According to neoclassical theory, the price paid for fuel should be proportional to its marginal product (Stern, 2011).
} 


\subsubsection{Sector level or level of the total economy?}

Recent studies investigate the causality between energy consumption and economic growth at the sectoral level. Based on the ARDL bounds testing procedure as proposed by Pesaran and Shin (1999) and Pesaran et al. (2001), Zachariadis (2007) finds evidence for short-run Granger causality running from economic growth to energy for the commercial sector as well as for the transport sector. However, for the transport sector, Zachariadis uses total GDP and final energy consumption as a pair of variables. In our view, this choice is not appropriate, because the share of value added of the transport sector in total GDP is almost negligible. Thus, the scope of economic activity covered by total GDP does not correspond to the scope of economic activity covered by the energy consumption of the transport sector. A more technical reason for the mismatch of both variables is the fact that the price index of total GDP does not correspond to the price index of transport value added.

Bowden and Payne (2009) take the sectoral (final) energy consumption and total GDP as a pair of variables. Similar to the case of Zachariadis' analysis, there is a mismatch between the level of economic activity when total GDP is paired with the sectoral level of energy consumption.

To sum up, we consider final energy consumption (measured in thermal equivalents) and economic growth at the sectoral level an appropriate pair of variables for our causality analysis. Moreover, we assume that a multivariate causality analysis should be preferred to a bivariate approach in order to avoid omitted variable bias. The choice of control variables is based on major findings from the EKC literature as well as its critical reflections and will be discussed in the following.

\subsection{Energy productivity of the capital stock}

Fig. 1 indicated an increasing divergence between economic growth and energy consumption. Despite the different scales in each sector, this finding is evident both for the total economy as well as for the three sectors. Technological advances are typically incorporated to the economy through investment (Baily et al., 1981). When old capital goods get less and less (energy) efficient over time, firms are likely to scrap them. Since new vintages are less energy consuming, firms may decide to replace the oldest and less efficient machinery. Since different vintages of capital goods coexist, there should be a smooth increase of the capital to energy ratio over time. Evidence for correlation between the energy efficiency of production and the ratio of capital and energy consumption was found by Wang (2007) and Wang (2011). The assumption of complementarity between capital goods and energy consumption is consistent with the empirical evidence put forward by Hudson and Jorgenson (1974), or Berndt and Wood (1975).

Including the capital to energy ratio in the analysis provides a direct measure of changes in energy productivity embodied in the newly produced capital goods. In our view, any neglect of the role of energy productivity would inevitably lead to an undervaluation of the role of energy consumption for economic growth and vice versa ${ }^{12}$. Also implications from Granger causality tests are eventually misleading if the increasing energy productivity of the capital stock is not considered $^{13}$. In order to account for price induced replacements of the capital stock, we also suggest to control for the average energy price paid for in each sector.

\subsection{Goods, services, and international trade}

While accounting for the capital to energy ratio enables us to control for the increasing energy productivity, Fig. A.4.1, in addition, reveals a seemingly arbitrary development starting in the

\footnotetext{
${ }^{12} \mathrm{An}$ increase of the capital to energy ratio in previous periods could, for example, explain why output grows although the amount of energy consumption remained constant (or even decreased).

${ }^{13}$ If the amount of energy consumption stays constant, while output grows, energy is still equally important in absolute terms, but a Granger causality analysis between energy and growth alone would eventually discard the Granger causal relationship. Controlling for structural breaks could solve this problem, but not explain the underlying development.
} 
mid 1970s, by which only the industry sector is affected. A fundamental difference among the three sectors is the degress to which the production chain can be separated. The industry sector is a goods producing sector, while both transportation as well as the commercial sector provide services. The production process of services is inseparable and must necessarily - apart from a few exceptions - be provided in the home country. In the case of the goods producing industry sector the production process can be separated and parts of the value added chain can be offshored to foreign countries. In the home country, the separability of the production of goods affects the relationship between energy and growth in two ways: (1) the import of intermediate goods distorts the price level of national statistics via an imprecise calculation of the Producer's Price Index (PPI), which leads to an overvaluation of value added in the industry sector. (2) The indirect amount of energy consumption associated with non-energy (intermediate) imports is not accounted for in national statistics (e.g. from the BEA). This leads to an underestimation of the energy associated with the production of final goods within the borders of the U.S.

Regarding the biased intermediate input price index, Houseman et al. (2010) argue that the dramatic acceleration of imports from developing countries is imparting a significant bias to official statistics: Yeats (2001) found that 30\% of world trade in manufacturing are intermediate inputs. Bardhan and Jaffee (2004) found that intermediate inputs represent 37 to $38 \%$ in the imports to the US for years 1992 and 1997, whereas the percentage of intrafirm trade grew from $43 \%$ in 1992 to $52 \%$ in 1997. Price declines associated with the shift to lowcost foreign suppliers generally are not captured in price indices. Thus, the deflation of current value added also necessitates an adjustment for the value of imported intermediate inputs whose price changes might not be accurately reflected in deflators based on domestic products, such as the PPI (see also OTA, 1990). The bias of the input price index will be proportional to the share captured by low-cost suppliers and the percentage discount offered by the low-cost suppliers (Diewert and Nakamura, 2009). If growth in the input price index is overstated, productivity and real value added will also be overstated.

Regarding the neglect of indirect energy consumption, The Office of Technology Assessment (1990) estimates that to assemble all of the motor vehicles made in 1985 requires more than five times higher indirect energy consumption than direct energy consumption. The "division between direct and indirect energy use is especially appropriate when the energy associated with international trade is considered. [...] Nevertheless, as production networks continue to extend beyond a country's borders, the inclusion of the indirect energy embodied in the trade of nonenergy products is increasingly important in calculating a country's total energy use" (OTA, 1990, p. 3). In the context of the EKC, Suri and Chapman (1998) show that industrialized countries have been able to reduce their energy requirements by importing (intermediate) manufactured goods. Once openness - measured as the trade to GDP ratio - is controlled for, Suri and Chapman can explain large parts of the downward slope of the EKC.

Incentives for offshoring of energy-intensive production have also been investigated in the EKC literature: the PHH states that differences in environmental regulations between developed and developing countries may be compounding a general shift away from industry production in the developed world and causing developing countries to specialize in the most pollution intensive industry sectors. Since the costs of meeting environmental regulations are undoubtedly far lower in most developing countries than in developed countries, it is possible that developing countries may possess a comparative advantage in pollution-intensive production (see Cole, 2004 for an overview). As a consequence, trade liberalization or openness (Harrison, 1996) will lead to more rapid growth of pollution intensive industries in less developed economies (Tobey, 1990; Rock, 1996). Several studies could not find empirical evidence for offshoring of pollution (see Aguayo and Gallagher, 2005; Kander and Lindmark, 2006; Levinson, 2010). Accordingly, we restrict our interpretation of the implications from the PHH to the offshoring of energy consumption - not necessarily pollution - to foreign countries.

In order to control for the biased input price index as well as the neglect of indirect energy 
consumption, we suggest to account for trade in our causality analysis. It allows us to control for the total energy consumption (here defined as the sum of direct and indirect final energy consumption) needed for the production of final goods within the borders of the U.S. Although the growth of the U.S. industry sector is not directly affected by (shortages in) the energy supply in exporting nations, the production chain in the U.S. sensitively depends on the availability of intermediate manufactured goods from exporting nations. Accordingly, the internalization of the indirect energy consumption related to the production of final goods in the U.S. is, in our view, necessary to be included in the following empirical analysis.

\section{Data and econometric methodology}

For the analysis of cointegration between energy consumption and economic growth, we use the ARDL bounds testing procedure recently developed by Pesaran and Shin (1999) and Pesaran et al. (2001). There are several advantages of the ARDL approach over alternatives such as those suggested by Engle and Granger (1987) and Johansen and Juselius (1990). (1) Here, it is not a prerequisite to examine the non-stationarity property and order of integration of the variables; (2) bounds tests produce robust results also for small sample sizes like the present one(Pesaran and Shin, 1999) and (3) empirical studies have established that energy market-related variables are either integrated of order $1[I(1)]$ or $I(0)$ in nature and one can rarely confronted with $I(2)$ series (Narayan and Smyth, 2007, 2008), justifying the application of ARDL for our analysis (see also Ghosh, 2009). Narayan (2005) added tables with critical F values for sample size ranging from 30 to 80 in the tables provided by Pesaran and Shin. As our sample size is within this range, we will use the critical values provided by Narayan. The ARDL bounds testing procedure involves three steps: (1) we conduct a Phillips-Perron test to ensure that the variables are not $I(2),(2)$ we apply an unrestricted error correction model (ECM) to test for cointegration among the variables. If evidence for a long-run relationship can be found, we calculate an error correction term (ECT), which contains information about the long-run relationship ${ }^{14}$. (3) We examine the existence of long-run ('strong') and short-run ('weak') Granger causality in an restricted ECM. This test provides information about a long-run relationship as well as short-run dynamics.

\subsection{Data description}

Data on GDP as well as sectoral value added are provided by the BEA for the U.S. and cover the period from 1970 to $2007^{15}$. We used sector-specific value added deflators for sectoral value added and a GDP deflator for total GDP to transform the output measure into constant prices. The deflators are provided by the same source. The NAICS-based data on value added are available for three sectors - industry (including agriculture, mining, manufacturing), commerce (wholesale trade, retail trade, information, finance, insurance, real estate, rental and leasing, professional and business services, educational services, health care and social assistance, arts, entertainment, recreation, accommodation and food services, and government), as well as transport (transportation and warehousing). The energy input is measured as final (sectoral) energy consumption in Btu. Energy data are provided by the U.S. Energy Information Administration and cover the same sectors as the output data. Data on average sectoral (constant) energy prices are provided by the same source. Trade is approximated by the import penetration rate in constant prices. It is measured as the ratio between imports and domestic demand. It shows to what degree domestic demand is satisfied by imports. The data provided by the OECD allows to differentiate between import

\footnotetext{
${ }^{14}$ Otherwise, those information would be lost in a first-differenced restricted ECM.

${ }^{15}$ Although the BEA dataset ranges from 1949 to 2009, we had to shorten the time period because the capital and trade data are available only from 1970 to 2007. To test the results of the bivariate cases for robustness, we conducted the tests also for the full period (not reported). We found that the results for the full period did not significantly deviate from the results for the period from 1970 to 2007.
} 
Table 2 - Results of the Phillips-Perron test

\begin{tabular}{llcc}
\hline Sector & Variable & Level & First difference \\
\hline Total & $Y$ & -.056 & $-4.912^{* * *}$ \\
& $E C$ & -1.187 & $-4.675^{* * *}$ \\
Industry & $Y$ & .399 & $-5.147^{* * *}$ \\
& $E C$ & -2.146 & $-5.633^{* * *}$ \\
& $E P$ & -3.119 & $-3.773^{* * *}$ \\
& $C A P$ & -1.575 & $-4.653^{* * *}$ \\
& $T R A D E$ & .297 & $-5.128^{* * *}$ \\
Commercial & $Y$ & .010 & $-4.863^{* * *}$ \\
& $E C$ & -.818 & $-6.055^{* * *}$ \\
& $E P$ & $-2.668^{*}$ & $-4.589^{* * *}$ \\
& $C A P$ & -.395 & $-6.231^{* * *}$ \\
& $T R A D E$ & .009 & $-5.565^{* * *}$ \\
Transport & $Y$ & 1.255 & $-5.729^{* * *}$ \\
& $E C$ & -1.174 & $-3.819^{* * *}$ \\
& $E P$ & -1.549 & $-5.396^{* * *}$ \\
& $C A P$ & .064 & $-3.253^{* *}$ \\
\hline
\end{tabular}

Notes. $^{* * *}, * *, *$ denotes $1 \%, 5 \%, 10 \%$ level of significance

penetration of goods and import penetration of services. We chose import penetration of goods as a proxy for trade in the industry sector and import penetration of services for the commercial sector. As the task of transportation cannot be separated or offshored, we assume that trade does not have to be controlled for the in the transport sector ${ }^{16}$. The capital to energy ratio is calculated from the EU-KLEMS data base as the real fixed capital stock divided by energy consumption. The data are also NAICS-based and selected for the same industries as described above. The real fixed capital stock is calculated in constant prices and includes all assets, except for software. We did this recalculation in order to circumvent valuation problems related to intangible assets. Let $Y$, $E C, E P, C A P$ and $T R A D E$ represent output (GDP in the case of the total economy and value added in the case of the sectors), final energy consumption, energy price, capital to energy ratio and trade. All variables have been transformed to logs.

\subsection{Stationarity}

Although the ARDL modelling approach does not require unit root tests to test whether all variables are $I(0)$ or $I(1)$, it is important to conduct the unit root test in order to ensure that no variable is $I(2)$ or higher. If a variable is found to be $I(2)$, then the critical F-statistics, as computed by Pesaran et al. (2001) and Narayan (2005), are no longer valid. For stationarity tests we use the semi-parametric Philips-Perron test, as proposed by Phillips and Perron (1988). The results of the stationarity tests (see Table 2 ) show that most of the variables are non-stationary at level. After differencing the variables once, all variables are confirmed to be stationary. As non of the variables is integrated of order two, the ARDL bounds procedure can be used to examine the existence of a long-run relationship in the following step.

\subsection{Cointegration}

The notation of a multivariate unrestricted ECM in first log-differences for the ARDL $\left(p, q_{1} \ldots, q_{n}\right)$ bounds approach with two regressors is:

\footnotetext{
${ }^{16}$ We also took other measures for trade into consideration, for example, the trade to GDP ratio (see Suri and Chapman, 1998), but found that import penetration is the most adequate proxy for our analysis.
} 
Table 3 - Model Specifications

\begin{tabular}{clllll}
\hline & Depend. & Explan. & \multicolumn{3}{c}{ Control variables } \\
Model & variable & variable & EP & CAP & TRADE \\
\hline $\mathrm{A}$ & $x$ & $y$ & - & - & - \\
$\mathrm{B}_{1}$ & $x$ & $y$ & $\checkmark$ & - & - \\
$\mathrm{B}_{2}$ & $x$ & $y$ & - & $\checkmark$ & - \\
$\mathrm{B}_{3}$ & $x$ & $y$ & - & - & $\checkmark$ \\
$\mathrm{C}_{1}$ & $x$ & $y$ & $\checkmark$ & $\checkmark$ & - \\
$\mathrm{C}_{2}$ & $x$ & $y$ & $\checkmark$ & - & $\checkmark$ \\
$\mathrm{C}_{3}$ & $x$ & $y$ & - & $\checkmark$ & $\checkmark$ \\
$\mathrm{D}$ & $x$ & $y$ & $\checkmark$ & $\checkmark$ & $\checkmark$ \\
\hline
\end{tabular}

$E C$ to $Y$ and $x=E C, y=Y$ vice versa; $x \neq y$.

$$
\Delta Y_{i t}=\mu+\alpha Y_{i t-1}+\theta E C_{i t-1}+\lambda C_{i t-1}+\sum_{j=1}^{p-1} \gamma_{j} \Delta Y_{i t-j}+\sum_{j=0}^{q_{1}-1} \psi_{j} \Delta E C_{i t-j}+\sum_{j=0}^{q_{2}-1} \omega_{j} \Delta C_{i t-j}+u_{i t}
$$

The residual term, $u$, is assumed to be a white noise error process. The model is tested for $i=$ Total economy, Industry, Commercial, and Transport. $C$ is a place holder for a control variable. Depending on the model specification (see Table 3) we use one explanatory variable and up to three control variables. In the bivariate case, the individual lag length of $\Delta Y_{i t}$ and $\Delta E C_{i t}$ is denoted by $p$ and $q_{1}$, respectively. In the multivariate case, the lag length of $\Delta C_{i t}$ is denoted by $q_{1}$. The optimal lag order is selected following the minimum values of the Bayesian information criterion (BIC). According to Pesaran et al. (2001), the BIC is generally used in preference to other criteria because it tends to define more parsimonious specifications. Using $\mu$ as an intercept term in first differences allows the estimation of a deterministic trend in the levels of the variables. In the bivariate case, the null hypothesis of 'no long-run relationship' is tested with the aid of an F-test of the joint significance of the lagged level coefficients: $H_{0}: \alpha=\theta=0$ against $H_{1}$ : $\alpha \neq \theta \neq 0$. In the multivariate case, the null hypothesis of 'no long-run relationship' is: $H_{0}$ : $\alpha=\theta=\lambda=0$ against $H_{1}: \alpha \neq \theta \neq \lambda \neq 0$. As long as it can be assumed that the error term $u_{t}$ is a white noise process, or is stationary and independent of $E C_{i t}, E C_{i t-1}$, and $Y_{i t}, Y_{i t-1}$ (and $C_{i t}$, $C_{i t-1}$ in the multivariate case), the ARDL models can be estimated consistently by ordinary least squares. The null hypothesis of no cointegration will be rejected provided the upper critical bound is less than the computed F-statistic. Finally, there will be no decision about cointegration if the computed F-statistics is between lower and upper critical bounds. In order to test the reversed cointegration relationship between $E C$ and $Y$, the unrestricted ECM model is tested with $\triangle E C_{i t}$ as the dependent variable and $\Delta Y_{i t}$ as the forcing variable in the bivariate case. In the multivariate case, the cointegrating relationship between $E C, Y$ and $C$ if $Y$ and $C$ are the forcing variables is tested with $\Delta E C_{t}$ as the dependent variable.

In case we reject the null hypothesis of no cointegration in Eq. (1), we calculate an ECT by $\widehat{\xi_{i t}}=Y_{i t}-\widehat{\beta} E C_{i t}$, where $\widehat{\beta}=-\frac{\widehat{\theta}}{\widehat{\alpha}}$ and $\widehat{\alpha}$ and $\widehat{\theta}$ are the OLS estimators in the bivariate case. In the multivariate case, we calculate an error correction term by $\widehat{\xi_{i t}}=Y_{i t}-\widehat{\beta} E C_{i t}-\widehat{\delta} C_{i t}$, where $\widehat{\beta}=-\frac{\widehat{\theta}}{\widehat{\alpha}}, \widehat{\delta}=-\frac{\widehat{\lambda}}{\widehat{\alpha}}$ and $\widehat{\alpha}, \widehat{\theta}$ and $\widehat{\lambda}$ are the OLS estimators obtained from the ARDL model. To be theoretically meaningful the coefficient of the ECT should be negative and range between zero and one in absolute term. This ensures the ECT maintains the equilibrium relationship between the cointegrated variables over time.

We estimate the unrestricted ECM for various combinations of forcing variables, as summerized 
in Table 3. The bivariate Model A is the reference model with only $Y$ and $E C$ as a pair of variables. Models $\mathrm{B}_{1}, \mathrm{~B}_{2}$, and $\mathrm{B}_{3}$ are augmented by $E P, C A P$, and $T R A D E$, respectively. Models $\mathrm{C}_{1}, \mathrm{C}_{2}$, and $\mathrm{C}_{3}$ contain sets of two control variables. Model $\mathrm{D}$ is the full model including all variables. Tests are conducted for the total economy, the industry sector, the commercial sector, as well as the transport sector. Given the large number of model specifications we will, in an intermediate step, select those models for which we find evidence for cointegration and which minimize the BIC. We will also include the basic Model A as a reference model.

\subsection{Long-run and short-run Granger causality}

Having found that there exists a long-run relationship between the variables, the next step is to test for the existence of Granger causality between the variables. Engle and Granger (1987) showed that if the series $X$ and $Y$ are individually $I(1)$ and cointegrated then there would be a causal relationship at least in one direction. A time series $(X)$ is then said to Granger-cause another time series $(Y)$ if the prediction error of current $Y$ declines by using past values of $X$ in addition to past values of $Y$. This concept of causality is generally accepted in the energygrowth literature. However, we are aware of Zellner's (1979) objection to the concept of Granger causality ${ }^{17}$. Concerning Zellner's objection to the atheoretical approach of Granger causality, we suggest to include well-established findings from the EKC literature. In order to test for Granger long-run and Granger short-run causality in the bivariate case, we run an restricted ECM of $\Delta Y$ on $\eta \widehat{\xi}, \Delta E C,(p-1)$-lagged $\Delta Y$ 's and $\left(q_{1}-1\right)$-lagged $\Delta E C$ 's. In the multivariate case, we run additional tests on the $\left(q_{2}-1\right)$-lagged $\Delta C$ 's according to

$$
\Delta Y_{i t}=\mu+\eta \widehat{\xi_{i t-1}}+\sum_{j=1}^{p-1} \gamma_{j} \Delta Y_{i t-j}+\sum_{j=0}^{q_{1}-1} \psi_{j} \Delta E C_{i t-j}+\sum_{j=0}^{q_{2}-1} \omega_{j} \Delta C_{i t-j}+u_{i t} .
$$

The coefficient of the ECT $\eta$ is a measure of long-run Granger causality between $Y$ and EC (and $C$ ). The null hypothesis of no long-run Granger causality is: $H_{0}: \eta=0$ against $H_{1}: \eta \neq 0$. If no long-run relationship between $Y$ and $E C$ (and $C$ ) has been found in Eq. (1), we test the same model with $\eta \widehat{\xi_{i t-1}}=0$ (see Ghosh, 2009). An F test on the $\left(q_{1}-1\right)$-lagged $\Delta E C$ indicates the significance of short-run Granger causality between $Y$ and $E C$. Analogously, an F test on the $\left(q_{2}-1\right)$-lagged $\Delta C$ 's indicates the significance of Granger short-run causality between $Y$ and $C$. Hence, the null hypothesis that $E C$ does not Granger-cause $Y$ in the short run is $H_{0}: \psi_{j}=0$ against $H_{1}: \psi_{j} \neq 0$. The null hypothesis that $C$ does not Granger-cause $Y$ in the short run is $H_{0}: \omega_{j}=0$ against $H_{1}: \omega_{j} \neq 0$. In contrast to long-run Granger causality, short-run Granger causality is a measure for weak Granger causality. As it is only a test on the joint significance of the $(q-1)$-lagged differences of the explanatory variables, any long-run information is removed. In addition, Eq. (2) also contains a contemporaneous term of the explanatory variable(s). When the contemporaneous term is included, one seeks to determine whether relationships can be determined 'simultaneously' (i.e., at a higher frequency than reported in the dataset) as opposed to any of the variables leading the other ${ }^{18}$. In order to test both the long-run and short run Granger causality from $Y$ (and $C$ ) to $E C$, the restricted model is tested with $\Delta E C_{i t}$ as the dependent variable.

\footnotetext{
${ }^{17}$ Zellner (1979) criticizes that "it is not satisfactory to identify cause with temporal ordering, as temporal ordering is not the ordinary, scientific or philosophical foundation of the causal relationship. Second, Granger's approach is atheoretical. In order to implement it practically, an investigator must impose restrictions - limit the information set to a manageable number of variables [...]" (see also Hoover, 2008).

${ }^{18}$ For the U.S., Zarnikau (1996) analyzes instantaneous Granger causality. He finds evidence for bi-directional instantaneous Granger causality.
} 
Table 4 - Results of Unrestricted ECM

\begin{tabular}{lccccc}
\hline & \multicolumn{5}{c}{ Dependent variable } \\
Sector & Model & F-statistics & BIC & F-statistics & BIC \\
\hline Total & $\mathrm{A}$ & 2.24 & -205.91 & 4.28 & -198.06 \\
Industry & $\mathrm{A}$ & .23 & -127.77 & 1.96 & -143.00 \\
& $\mathrm{~B}_{1}$ & .17 & -122.91 & 2.10 & -139.41 \\
& $\mathrm{~B}_{2}$ & .79 & -125.82 & 1.82 & $-258.19^{-}$ \\
& $\mathrm{B}_{3}$ & 1.92 & $-145.42^{-}$ & 1.13 & -144.99 \\
& $\mathrm{C}_{1}$ & 1.18 & -121.65 & 1.92 & -254.77 \\
& $\mathrm{C}_{2}$ & 2.42 & -139.72 & 1.22 & -137.67 \\
& $\mathrm{C}_{3}$ & 2.24 & -139.15 & 2.25 & -252.96 \\
& $\mathrm{D}$ & 1.66 & -133.48 & 1.57 & -248.06 \\
Commercial & $\mathrm{A}$ & 1.75 & -158.26 & 3.93 & -161.66 \\
& $\mathrm{~B}_{1}$ & 1.31 & -153.57 & 3.16 & -157.51 \\
& $\mathrm{~B}_{2}$ & 3.45 & $-169.44^{-}$ & $6.45^{* *}$ & $-299.29^{-}$ \\
& $\mathrm{B}_{3}$ & 1.34 & -154.11 & 2.32 & -156.09 \\
& $\mathrm{C}_{1}$ & 3.16 & -169.31 & 3.35 & -294.37 \\
& $\mathrm{C}_{2}$ & 0.86 & -149.24 & 3.16 & -153.03 \\
& $\mathrm{C}_{3}$ & 2.88 & -162.67 & $4.5^{*}$ & -295.44 \\
& $\mathrm{D}_{5}$ & 2.20 & -163.44 & 2.44 & -290.93 \\
& & & & & \\
Transport & $\mathrm{A}$ & $8.80^{* * *}$ & $-131.79^{-}$ & $10.56^{* * *}$ & -193.63 \\
& $\mathrm{~B}_{1}$ & 1.86 & -123.93 & $4.89^{*}$ & -183.39 \\
& $\mathrm{~B}_{2}$ & 3.21 & -130.05 & $6.36^{* *}$ & $-227.47^{-}$ \\
& $\mathrm{C}_{1}$ & 2.48 & -128.01 & $4.60^{*}$ & -220.85 \\
\hline
\end{tabular}

Notes. ${ }^{* * *},{ }^{* *},{ }^{*}$ denotes $1 \%, 5 \%, 10 \%$ level of significance; ${ }^{-}$denotes the minimum BIC per sector. The critical values from Narayan (2005) are presented in Table A4.

\section{Empirical results and discussion}

\subsection{Results of the cointegration tests and model selection}

The results for the bounds cointegration test are reported in Table 4. The corresponding lag lengths are shown in Table A.2. We tested the model for a minimum lag order of null and a maximum lag order of three.

\subsubsection{Total economy}

For the total economy, we cannot find evidence for cointegration. This is because the corresponding F-Tests on the lagged levels of the explanatory variables are lower than the upper bound critical values reported by Narayan (2005), see Table A.4. Thus, there exists no long-run relationship between energy consumption and growth at the level of the total economy. As no long-run relationship between energy and output exists in either direction, we also cannot calculate an ECT from the regression results. In order to investigate the short-run dynamics, we will run an restricted ECM on Model A in the next step.

\subsubsection{Industry sector}

There is no evidence for cointegration between energy and growth in the industry sector. Despite the inclusion of control variables, the relative development of both variables (see Fig. A.4.1) is 
too random for the identification of a long-run relationships. Model $\mathrm{B}_{3}$ minimizes the $\mathrm{BIC}$ when output is the dependent variable and Model $\mathrm{B}_{2}$ minimizes the BIC when energy is the dependent variable. These models will be tested for the existence of short-run dynamics in addition to the basic Model A. This intermediate result indicates that it is important to allow for different sets of explanatory variables, because output seems to be better explained by trade (in addition to energy), while energy seems to be better explained if the capital to energy ratio is added to the basic model.

\subsubsection{Commercial sector}

We find evidence for cointegration in the commercial sector (Model $\mathrm{B}_{2}, \mathrm{C}_{3}$ ) when energy is the dependent variable. This is because the corresponding F-Tests on the lagged levels of the explanatory variables are higher than the corresponding upper bound critical values. We cannot find evidence for cointegration if energy is the dependent variable. Accordingly, the long-run relationship in the commercial sector is forced rather by economic growth than by the use of energy. This result is a common result, because the growth of the commercial sector has been driven rather by its high degree of employment ${ }^{19}$. From an econometric point of view, the result of uni-directional cointegration is not unusual, because mutual cointegration is not necessarily evident in the multivariate case. As Model $\mathrm{B}_{2}$ minimizes the BIC when energy is the depending variable, we will also run an restricted ECM on this specification.

\subsubsection{Transport sector}

For the transport sector, we find evidence for cointegration when output is the dependent variable (Model A) as well as when energy is the dependent variable (Model A, $\mathrm{B}_{1}, \mathrm{~B}_{2}, \mathrm{C}_{1}$ ). Interestingly, we find only evidence for mutual cointegration in the bivariate case. Once the energy price and / or energy productivity is controlled for, the long-run relationship breaks when output is the dependent variable. This result indicates that the causal relationship between energy consumption and economic growth is not at all carved in stone, but can be broken up by efforts to increase the energy productivity of the capital stock and the development of energy prices. The comparison with the other sectors shows that the 'neutralization' of the cointegrating relationship can only be achieved in the transport sector. A possible interpretation of this evidence can be deducted from the fundamental difference between the transport sector and the other sectors: the production process of the transport sector is inseparable and highly energy intensive. On the one hand, there is not the opportunity of offshoring like in the case of the industry sector, which could have distorted the relationship before. Accordingly, changes in energy prices and improvements of the capital to energy ratio immediately affect the energy-growth relationship without any chance of elusion like in the industry sector. On the other hand, energy is an essential factor input in the transport sector. Compared to the labor intensive commercial sector, developments affecting the energy input thus have a stronger impact on the energy-growth relationship.

To sum up, the results of the cointegration tests emphasize the need to disaggregate the relationship between energy consumption and growth. The results from the cointegration tests at the level of the total economy 'hides' the evidence we find at the sectoral level ('Simpson's Paradox'). Once the long-term relationships have been established we will test the selected models for evidence for long-run as well as short-run Granger causality in the next step.

\subsection{Results of the long-run and short-run Granger causality tests}

The results for the long-run and short-run Granger causality tests are reported in Table 5. The corresponding lag lengths are shown in Table A.3.

\footnotetext{
${ }^{19}$ See, for example, Kander (2005) for a discussion of Baumol's (1967) cost disease in the context of the EKC literature.
} 


\subsubsection{Total Economy}

For reasons discussed above we excluded the ECT from the estimation of the restricted ECM. Accordingly, we conclude that there is also no evidence for long-run Granger causality in either direction. Concerning the results for short-run Granger causality, the F-Tests on the $(q-1)$-lagged explanatory variables show evidence for bi-directional Granger causality. The values in parentheses show the estimated regression coefficient for the $(q-1)$-lagged explanatory variables. It shows that the mutual impact is positive, whereas growth has a stronger effect on energy consumption than the other way around.

\subsubsection{Industry sector}

We find evidence for bi-directional short-run Granger causality in the industry sector for Model A. However, the value of the BIC indicates that the fit of the model can be improved if we control for trade, when output is the dependent variable (Model $B_{3}$ ). In this case, the positive effect of energy consumption on growth is almost halved and distributed among energy consumption and trade. The fact that Model $\mathrm{B}_{3}$ has a better fit, leads us to the conclusion that controlling for trade explains economic growth better than (direct) energy consumption alone ${ }^{20}$. Then, both the direct as well as the indirect amount of energy consumption incorporated in non-energy inputs Granger causes industry output in the short run. So far, policy implications derived from causality analyses have focused mainly on isolated energy policies in the home country. However, as the indirect amount of energy consumption also Granger causes growth, it becomes important for the importing country to internalize energy policies of exporting nations. If, for example, the U.S. government is willing to accept stricter environmental conditions - because its own industry sector has offshored energy-intensive parts of the value added chain - it does not necessarily have an incentive to advocate equal standards for all countries. This is especially the case for those countries with a comparative advantage in energy-intensive production. Otherwise, too strict regulations for exporting nations could also have a feedback effect on growth in the U.S.

When energy is the dependent variable, the fit of the basic model can be improved if we control for the capital to energy ratio (Model $\mathrm{B}_{2}$ ). The estimates for the regression coefficients indicate that the sign of the effect of energy productivity depends on the lag length. In $t$ the effect of an increase in the capital to energy ratio is negative, while the effect is positive in $t-1$. Thus, we cannot conclude whether the overall effect is more likely to be positive or negative. The empirical finding that technological progress positively affects the consumption of energy is known as the 'rebound effect' and was first discovered by William S. Jevons in 1864. In case we control for the capital to energy ratio, we cannot find evidence for short-run Granger causality between energy and output any more. This finding indicates that the effect of growth on energy consumption is not as strong as suggested in Model A. We argued before that, due to the separability of the production process in the industry sector, there are opportunities for bypassing an equal increase in energy consumption if output grows.

\subsubsection{Commercial sector}

For the basic model we cannot find evidence for Granger causality, both in the long run as well as in the short run. Accordingly, we find evidence for the neutrality hypothesis on all levels of investigation. The neutrality between energy consumption and growth supports our assumption that the transformation of the sectoral composition of the economy is one of the key elements, which distorts the evidence for Granger causality at the level of the total economy. As the commercial sector is the only sector, which has continuously grown over the last decades, the total economy is increasingly dominated by the commercial sector with respect its share in total GDP. As the growth in the commercial sector is neutral with respect to its energy consumption, there is no

\footnotetext{
${ }^{20}$ If trade is considered a proxy for the indirect amount of energy consumption.
} 


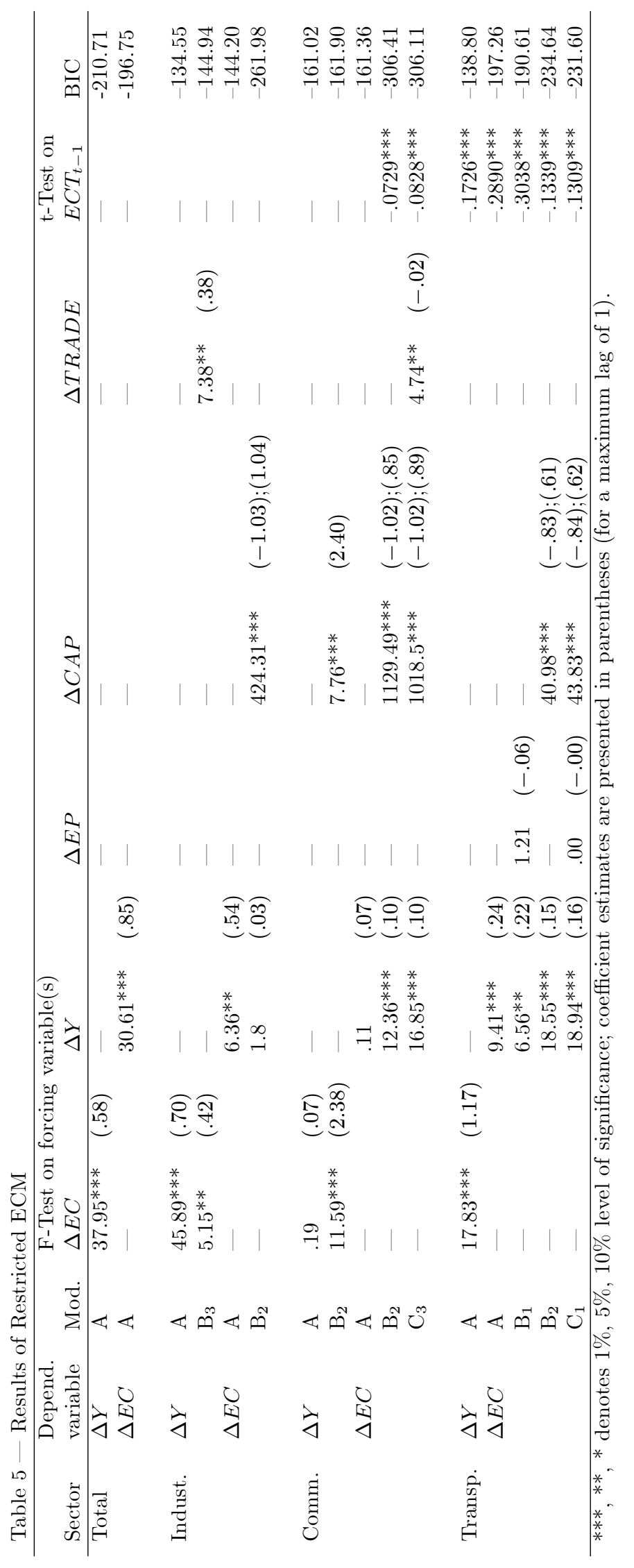


equal growth with respect to energy. Altogether, the results indicate that the tertiarization of the economy can be considered one of the reasons why Granger causality tests at the level of the total economy tend to understate the evidence of Granger causality at the sector level.

The fit of the basic model can be marginally increased if we add energy saving technological progress as a control variable (Model $\mathrm{B}_{2}$ ) when output is the dependent variable. We find that energy consumption and the capital to energy ratio Granger-cause growth in the short run. This result indicates that it is rather the replacement of the least energy efficient capital stock than the increase in absolute amounts of energy consumption, which is necessary for growth in the commercial sector.

In case energy is the dependent variable, the ECT is significant at the $1 \%$ level, which indicates long-run Granger causality if the capital to energy ratio $\left(\right.$ Model $\mathrm{B}_{2}$ ) and, in addition, trade (Model $\mathrm{C}_{3}$ ) is added to the basic model. The coefficient of the ECT indicates a low speed of adjustment to shocks to the forcing variables (13.7 years in Model $\mathrm{B}_{2} ; 12.1$ years in Model $\mathrm{C}_{3}$ ). This finding may be related to the complex and immobile energy infrastructure in the commercial sector. The main energy source consumed in the service serctor is electricity, which necessitates the installation of a complex electricity system. Comparing Model $\mathrm{B}_{2}$ and $\mathrm{C}_{3}$, the inclusion of trade does not improve the fit of Model $\mathrm{B}_{2}$, which corresponds to the results from Amiti and Wei $(2009)^{21}$. The effect of trade on energy consumption is marginally negative. Concerning the short-run Granger causality between the capital to energy ratio, we also find evidence for the rebound effect in both models. However, the effect is smaller than in the industry sector. Although the amount of energy consumption in the commercial sector is comparatively low, our finding suggests that the steady growth of the commercial sector will also raise the energy consumption in the future. As a consequence, the commercial sector may become more dependent on energy.

\subsubsection{Transport sector}

We find evidence for bi-directional long-run as well as short-run Granger causality in the transport sector (Model A). The coefficient of the ECT shows that the speed of adjustment to exogenous shocks to the forcing variables is much higher than in the commercial sector. Output adjusts to the long-run relationship after 3.5 years, while energy returns to the long-run relationship after 5.8 years. The estimates for the short-run coefficients confirm that growth in the transport sector strongly depends on energy consumption.

In case energy is the dependent variable, the fit of the model can be improved if the capital to energy ratio is included (Model $\left.\mathrm{B}_{2}\right)$. Again, we find weak evidence for the rebound effect, because the effect of increasing energy productivity on energy consumption is not negative throughout. We also find evidence for cointegration if energy prices are included (Model $\mathrm{B}_{1}, \mathrm{C}_{1}$ ), although the fit of the Models $\mathrm{B}_{1}$ and $\mathrm{C}_{1}$ is not improved compared to Models $\mathrm{A}$ and $\mathrm{B}_{2}$. We interpret this finding as weak evidence for the dependence of energy consumption on the development of energy prices. However, it is remarkable that energy prices seem to accelerate the recovery of energy consumption after a shock to output (3.3 years in Model $\mathrm{B}_{1}$, while the capital to energy ratio slows down the recovery (7.5 years in Model $\mathrm{B}_{2} ; 7.6$ years in Model $\mathrm{C}_{1}$ ).

\section{Conclusion}

We examined the Granger causal relationship between energy consumption and economic growth in the U.S. for the period from 1970 to 2007 for the total economy as well as for the industry sector, the commercial sector, and the transport sector. For our analysis we used the recently developed ARDL bounds testing approach as proposed by Pesaran and Shin (1999) and Pesaran et al. (2001).

\footnotetext{
${ }^{21}$ Amiti and Wei (2009) found that service offshoring is likely to be more skill intensive than material intensive. Moreover, service offshoring is a only a more recent phenomenon.
} 
Our paper contributes to the literature in several ways: (1) based on Zachariadis (2007), we analyze the existing energy-growth literature for the U.S. with respect to the choice of appropriate variable pairs for causality analyses and discuss why the evidence is ambiguous. We conclude that only sectoral value added together with sectoral final energy consumption covers the same scope of economic activity and that the sector level should be preferred to the level of the total economy. (2) We also emphasize the fundamental differences between goods and service producing industries and its implications for the energy-growth relationship in each sector. We argue that, due to the inseparability of the production chain of service producing industries, there exists a closer relationship between energy and growth than in goods producing industries. As the energy intensive production of intermediate goods can be offshored to developing countries with lower environmental regulations, the relationship between industry value added (accounted for in national statistics) and energy consumption (whereas the indirect consumption of energy is not accounted for) is weaker. (3) We combine the well-established methodology from the energy-growth literature with major findings from the EKC literature as well as its critical reflections. We show that augmenting the basic bivariate model with control variables for trade and energy productivity significantly improves the fit of several model specifications. (4) We find that Granger causality between energy consumption and economic growth are not always forced by the same (control) variables. This is the case when we do not find cointegration or the BIC is not minized for the same model where energy and growth are the dependent variables.

In contrast to most bivariate analyses at the level of the total economy, we conclude that the causal relationship between energy consumption and economic growth is much closer than is normally assumed. Our results confirm that long-run Granger causality between energy consumption and economic growth can rather be found at the sectoral level. We find evidence for bi-directional long-run Granger causality in the transport sector. However, once the increasing energy productivity of the capital stock is controlled for, the relationship breaks. In the commercial sector we find evidence for long-run Granger causality from growth to energy consumption, if energy productivity is controlled for. The fundamental difference between goods and service producing industries also shows the differential impact of trade on the energy-growth relationship. Once trade is controlled for, we find evidence for short-run Granger causality running from energy consumption and trade to growth in the industry sector.

Concerning the implications, which can be drawn from the results, we strongly recommend the choice of an appropriate level of aggregation for Granger causality analyses in the energy-growth literature. If evidence for Granger causality cannot be found at the level of the total economy, the implication that no causality exists at all is myopic ('Simpson's Paradox'). Even though no evidence for long-run Granger causality can be found at the level of the total economy, policies which aim at the reduction of energy consumption could, in fact, affect individual sectors, both in the long run as well as in the short run. International policies which aim at stricter environmental regulations for developing countries would also indirectly affect the home country if the indirect consumption of energy is not internalized. Finally, the long-run relationship between energy and growth is not carved in stone. We show that efforts to increase the energy productivity of the capital stock allow to disintegrate the long-run relationship between energy consumption and economic growth in the transport sector. As long as the 'rebound effect' of increasing energy productivity does not outweigh the conservation of energy, a de-coupling between energy consumption and economic growth is possible. However, for this purpose we have to be aware of the 'real' relationship between energy consumption and growth, which tends to be undervalued in inappropriate model specifications.

\section{References}

Abosedra, S., Baghestani, H., 1991. New evidence on the causal relationship between United States energy consumption and gross national product. Journal of Energy and Development 14 (2), 
$285-292$.

Aguayo, F., Gallagher, K., 2005. Economic reform, energy, and development: the case of Mexican manufacturing. Energy Policy 33 (7), 829-837.

Akarca, A., Long, T., 1980. On the relationship between energy and GNP: a reexamination. Journal of Energy and Development 5 (2), 326-31.

Alcott, B., 2005. Jevons' paradox. Ecological Economics 54 (1), 9-21.

Amiti, M., Wei, S., 2009. Service offshoring and productivity: Evidence from the US. The World Economy 32 (2), 203-220.

Ayres, R., Ayres, L., Martinas, K., 1996. Eco-thermodynamics: exergy and life cycle analysis. Center for the Management of Environmental Resources Working Paper 96/04/ INSEAD.

Ayres, R., Martinas, K., 1995. Waste potential entropy: the ultimate ecotoxic? The Jounal of Applied Economics 48, 95-120.

Ayres, R., Warr, B., 2009. The Economic Growth Engine: how Energy and Work Drive Material Prosperity. Edward Elgar Publishing, Cheltenham.

Baily, M. N., Gordon, R. J., Solow, R. M., 1981. Productivity and the Services of Capital and Labor. Brookings Papers on Economic Activity 1 (1), 1-65.

Bardhan, A., Jaffee, D., 2004. On Intra-Firm Trade and Multinationals: Foreign Outsourcing and Offshoring in Manufacturing. University of California, Berkeley, mimeo.

Baumol, W., 1967. Macroeconomics of unbalanced growth: the anatomy of urban crisis. The American Economic Review 57 (3), 415-426.

Berndt, E., Wood, D., 1975. Technology, prices, and the derived demand for energy. The Review of Economics and Statistics 57 (3), 259-268.

Berndt, E. R., 1978. Aggregate Energy, Efficiency, and Productivity Measurement. Annual Review of Energy 3 (1), 225-273.

Bowden, N., Payne, J. E., 2009. The causal relationship between U.S. energy consumption and real output: A disaggregated analysis. Journal of Policy Modeling 31 (2), 180-188.

Cheng, B., 1995. An investigation of cointegration and causality between energy consumption and economic growth. Journal of Energy and Development 21 (1), 73-84.

Chiou-Wei, S., Chen, C., Zhu, Z., 2008. Economic growth and energy consumption revisitedEvidence from linear and nonlinear Granger causality. Energy Economics 30 (6), 3063-3076.

Chontanawat, J., Hunt, L., Pierse, R., 2006. Causality between Energy Consumption and GDP: Evidence from 30 OECD and 78 Non-OECD Countries. Surrey Energy Economics Centre (SEEC), Department of Economics Discussion Papers 113.

Chontanawat, J., Hunt, L., Pierse, R., 2008. Does energy consumption cause economic growth?: Evidence from a systematic study of over 100 countries. Journal of Policy Modeling 30 (2), 209-220.

Cleveland, C., Costanza, R., Hall, C., Kaufmann, R., 1984. Energy and the US economy: a biophysical perspective. Science 225 (4665), 880-889. 
Cleveland, C., Kaufmann, R., Stern, D., 2000. Aggregation and the role of energy in the economy. Ecological Economics 32 (2), 301-318.

Cole, M. A., 2004. Trade, the pollution haven hypothesis and the environmental Kuznets curve: examining the linkages. Ecological Economics 48 (1), 71-81.

Diewert, W., Nakamura, A., November 2009. Bias in the Import Price Index due to Outsourcing: Can it be Measured? Conference on Measurement Issues Arising from the Growth of Globalization, Washington DC.

Engle, R. F., Granger, C. W. J., 1987. Co-Integration and Error Correction: Representation, Estimation, and Testing. Econometrica 55 (2), 251-276.

Ghosh, S., 2009. Electricity supply, employment and real GDP in India: evidence from cointegration and Granger-causality tests. Energy Policy 37 (8), 2926-2929.

Harrison, A., 1996. Openness and growth: A time-series, cross-country analysis for developing countries. Journal of Development Economics 48 (2), 419-447.

Henriques, S. T., Kander, A., 2010. The modest environmental relief resulting from the transition to a service economy. Ecological Economics 70 (2), 271-282, special Section: Ecological Distribution Conflicts.

Hong, N. V., 1983. Notes - Two Measures of Aggregate Energy Production Elasticities. The Energy Journal 4 (2), 172-177.

Hoover, K. D., September 2008. Causality in economics and econometrics, 2nd Edition. Palgrave Macmillan.

Houseman, S., Kurz, C., Lengermann, P., Mandel, B., 2010. Offshoring and the State of American Manufacturing. Upjohn Institute Working Papers, Kalamazoo, MI: W.E. Upjohn Institute 10166 .

Hudson, E., Jorgenson, D., 1974. US energy policy and economic growth, 1975-2000. The Bell Journal of Economics and Management Science 5 (2), 461-514.

Jevons, W., 1864. The Coal Question: An Inquiry Concerning the Progress of the Nation and the Probable Exhaustion of Our Coal Mines. Macmillan, London.

Johansen, S., Juselius, K., 1990. Maximum likelihood estimation and inference on cointegration with applications to the demand for money. Oxford Bulletin of Economics and Statistics 52 (2), 169-210.

Kahn, H., 1979. World economic development. Westview press, Boulder, Colorado.

Kander, A., 2005. Baumol's disease and dematerialization of the economy. Ecological economics 55 (1), 119-130.

Kander, A., Lindmark, M., 2006. Foreign trade and declining pollution in Sweden: a decomposition analysis of long-term structural and technological effects. Energy policy 34 (13), 1590-1599.

Kaufmann, R., 1994. The relation between marginal product and price in US energy markets: Implications for climate change policy. Energy Economics 16 (2), 145-158.

Kraft, J., Kraft, A., 1978. On the relationship between energy and GNP. Journal of Energy and Development 3 (2), 401-403. 
Levinson, A., 2010. Offshoring Pollution: Is the United States Increasingly Importing Polluting Goods? Review of Environmental Economics and Policy 4 (1), 63.

Marchetti, C., 1977. Primary energy substitution models: On the interaction between energy and society. Technological Forecasting and Social Change 10 (4), 345-356.

Murry, D., Nan, G., 1994. A definition of the gross domestic product-electrification interrelationship. Journal of Energy and Development 19, 275-283.

Narayan, P., 2005. The saving and investment nexus for China: evidence from cointegration tests. Applied Economics 37 (17), 1979-1990.

Narayan, P., Prasad, A., 2008. Electricity consumption-real GDP causality nexus: Evidence from a bootstrapped causality test for 30 OECD countries. Energy policy 36 (2), 910-918.

Narayan, P., Smyth, R., 2007. Are shocks to energy consumption permanent or temporary? Evidence from 182 countries. Energy policy 35 (1), 333-341.

Narayan, P. K., Smyth, R., 2008. Energy consumption and real GDP in G7 countries: New evidence from panel cointegration with structural breaks. Energy Economics 30 (5), 2331-2341.

OTA, 1990. Energy Use and the U.S. Economy. Vol. OTA-BP-E-57. U.S. Government Printing Office, Washington, DC.

Ozturk, I., 2010. A literature survey on energy-growth nexus. Energy Policy 38 (1), 340-349.

Panayotou, T., 1993. Empirical tests and policy analysis of environmental degradation at different stages of economic development. Working Paper WP238, Technology and Employment Programme, International Labour Office, Geneva 238.

Panayotou, T., Peterson, A., Sachs, J., 2000. Is the environmental Kuznets curve driven by Structural change? What extended time series may imply for developing countries. USAID Consulting Assistance on Economic Reform (CAER) II Project Discussion Paper 54.

Payne, J., 2010. Survey of the international evidence on the causal relationship between energy consumption and growth. Journal of Economic Studies 37 (1), 53-95.

Payne, J., Taylor, J., 2010. Nuclear energy consumption and economic growth in the US: an empirical note. Energy Sources, Part B: Economics, Planning, and Policy 5 (3), 301-307.

Payne, J. E., 2009. On the dynamics of energy consumption and output in the US. Applied Energy $86(4), 575-577$.

Pesaran, M., Shin, Y., 1999. An Autoregressive Distributed Lag Modelling Approach to Cointegrated Analysis. In: Strom, S. (Ed.), Econometrics and Economic Theory in the 20th Century: The Ragnar Frisch Centennial Symposium. Cambridge University Press, Cambridge, MA.

Pesaran, M. H., Shin, Y., Smith, R. J., 2001. Bounds testing approaches to the analysis of level relationships. Journal of Applied Econometrics 16 (3), 289-326.

Phillips, P., Perron, P., 1988. Testing for a unit root in time series regression. Biometrika 75 (2), 335 .

Rock, M. T., 1996. Pollution intensity of GDP and trade policy: Can the World Bank be wrong? World Development 24 (3), 471-479. 
Sari, R., Ewing, B., Soytas, U., 2008. The relationship between disaggregate energy consumption and industrial production in the United States: An ARDL approach. Energy Economics 30 (5), 2302-2313.

Schurr, S., Netschert, B., Eliasberg, V., Lerner, J., Landsberg, H., 1960. Energy in the American economy, 1850-1975. Johns Hopkins University Press, Baltimore, MD.

Schäfer, A., 2005. Structural change in energy use. Energy Policy 33 (4), 429-437.

Simpson, E., 1951. The interpretation of interaction in contingency tables. Journal of the Royal Statistical Society. Series B (Methodological) 13 (2), 238-241.

Smil, V., 2000. Energy in the Twentieth Century: Resources, Conversions, Costs, Uses, and Consequences. Annual Review of Energy and the Environment 25, 21-51.

Soytas, U., Sari, R., 2003. Energy consumption and GDP: causality relationship in G-7 countries and emerging markets. Energy Economics 25 (1), 33-37.

Soytas, U., Sari, R., 2006. Energy consumption and income in G-7 countries. Journal of Policy Modeling 28 (7), 739-750.

Soytas, U., Sari, R., Ewing, B., 2007. Energy consumption, income, and carbon emissions in the United States. Ecological Economics 62 (3-4), 482-489.

Stern, D., 2000. A multivariate cointegration analysis of the role of energy in the US macroeconomy. Energy Economics 22, 267-283.

Stern, D. I., 1993. Energy and economic growth in the USA: A multivariate approach. Energy Economics 15 (2), 137-150.

Stern, D. I., 2011. The role of energy in economic growth. Annals of the New York Academy of Sciences 1219 (1), 26-51.

Suri, V., Chapman, D., 1998. Economic growth, trade and energy: implications for the environmental Kuznets curve. Ecological Economics 25 (2), 195-208.

Thoma, M., 2004. Electrical energy usage over the business cycle. Energy Economics 26 (3), 463485 .

Tobey, J. A., 1990. The Effects of Domestic Environmental Policies on Patterns of World Trade: An Empirical Test. Kyklos 43 (2), 191-209.

Wang, C., 2007. Decomposing energy productivity change: A distance function approach. Energy $32(8), 1326-1333$.

Wang, C., 2011. Sources of energy productivity growth and its distribution dynamics in China. Resource and Energy Economics 33 (1), 279-292.

Warr, B., Ayres, R., 2010. Evidence of causality between the quantity and quality of energy consumption and economic growth. Energy 35 (4), 1688-1693.

Yeats, A., 2001. Just how big is global production sharing? In: Arndt, S., Kierzkowski, H. (Eds.), Fragmentation: New Production Patterns in the World Economy. Oxford Press, Oxford.

Yu, E., Choi, J., 1985. The causal relationship between energy and GNP: an international comparison. Journal of Energy and Development 10 (2), 249-272. 
Yu, E. S. H., Hwang, B.-K., 1984. The relationship between energy and GNP: Further results. Energy Economics 6 (3), 186-190.

Yu, E. S. H., Jin, J. C., 1992. Cointegration tests of energy consumption, income, and employment. Resources and Energy 14 (3), 259-266.

Zachariadis, T., 2007. Exploring the relationship between energy use and economic growth with bivariate models: New evidence from G-7 countries. Energy Economics 29 (6), 1233-1253.

Zarnikau, J., 1996. Reexamination of the causal relationship between energy consumption and gross national product. Journal of Energy and Development 21, 229-239.

Zarnikau, J., 1999. Defining 'total energy use' in economic studies: does the aggregation approach matter? Energy Economics 21 (5), 485-492.

Zellner, A., 1979. Causality and econometrics. In: Brunner, K., Meltzer, A. (Eds.), Three Aspects of Policy Making: Knowledge, Data and Institutions. Vol. 10. Carnegie-Rochester Conference Series on Public Policy, Amsterdam, North-Holland.

\section{A. Appendix}

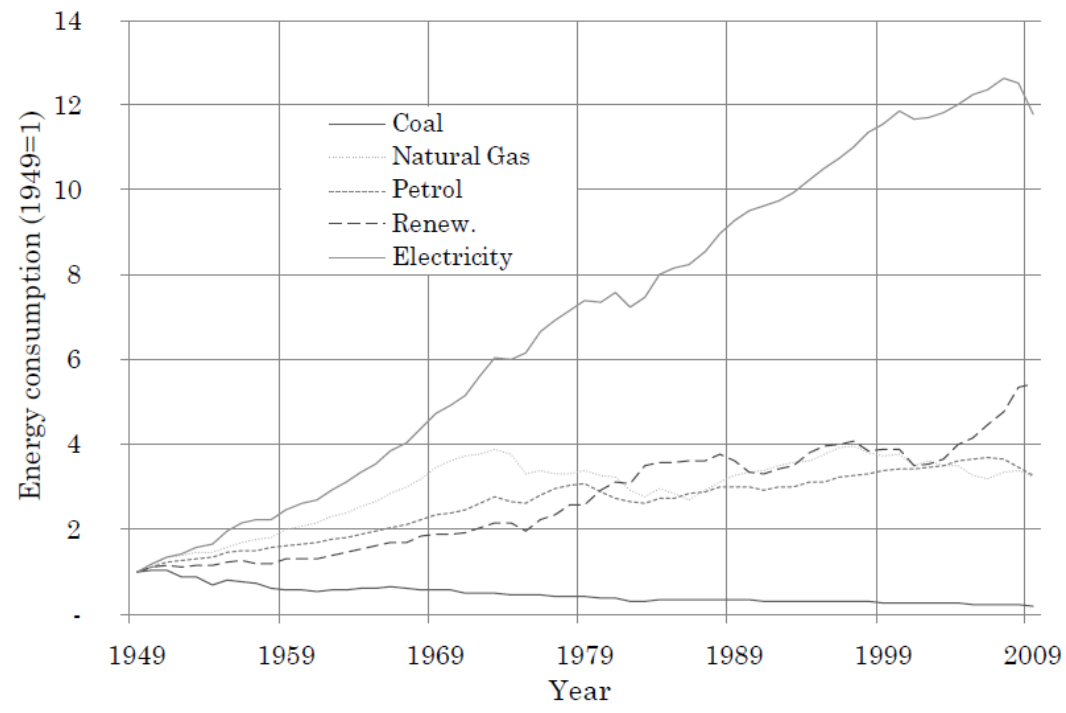

Fig. A.1: Consumption of different energy sources 1949-2009. 


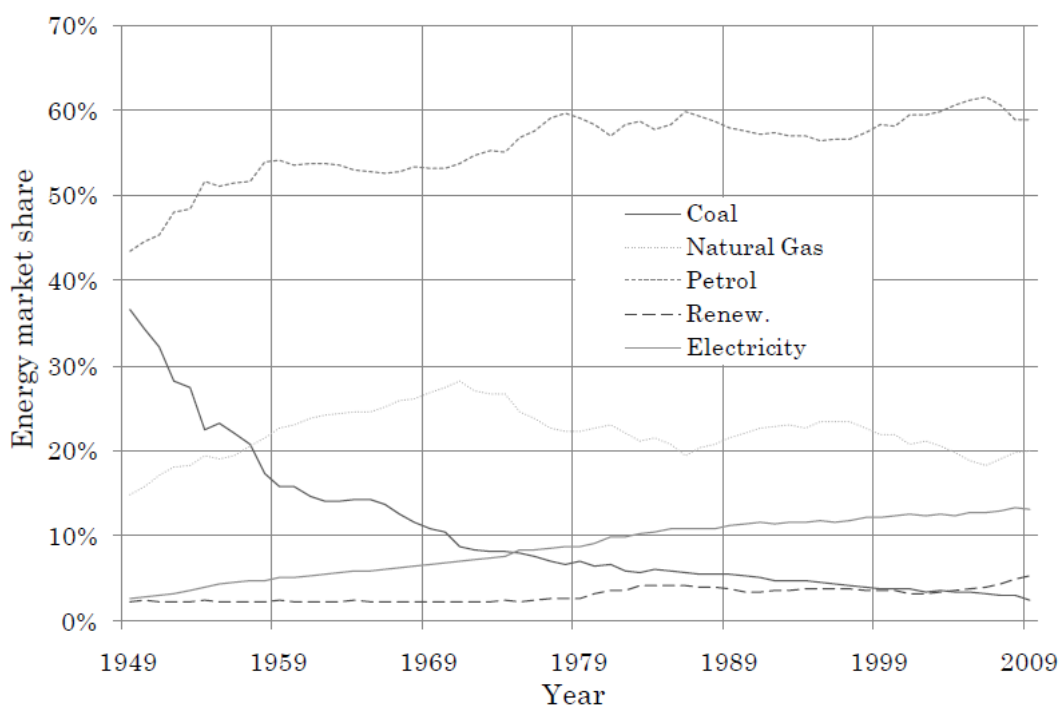

Fig. A.2: Market shares of different energy sources (Btu) 1949-2009.

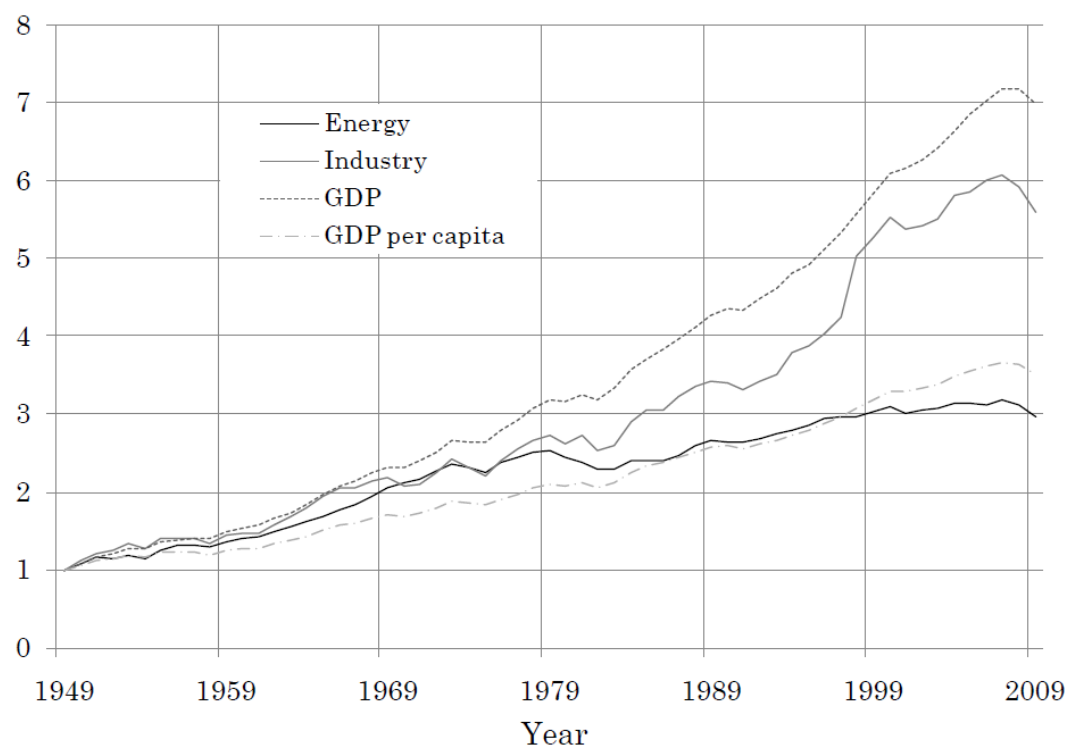

Fig. A.3: Development of energy, manufacturing value added, GDP, and GDP per capita 1949-2009 $(1949=1)$. 


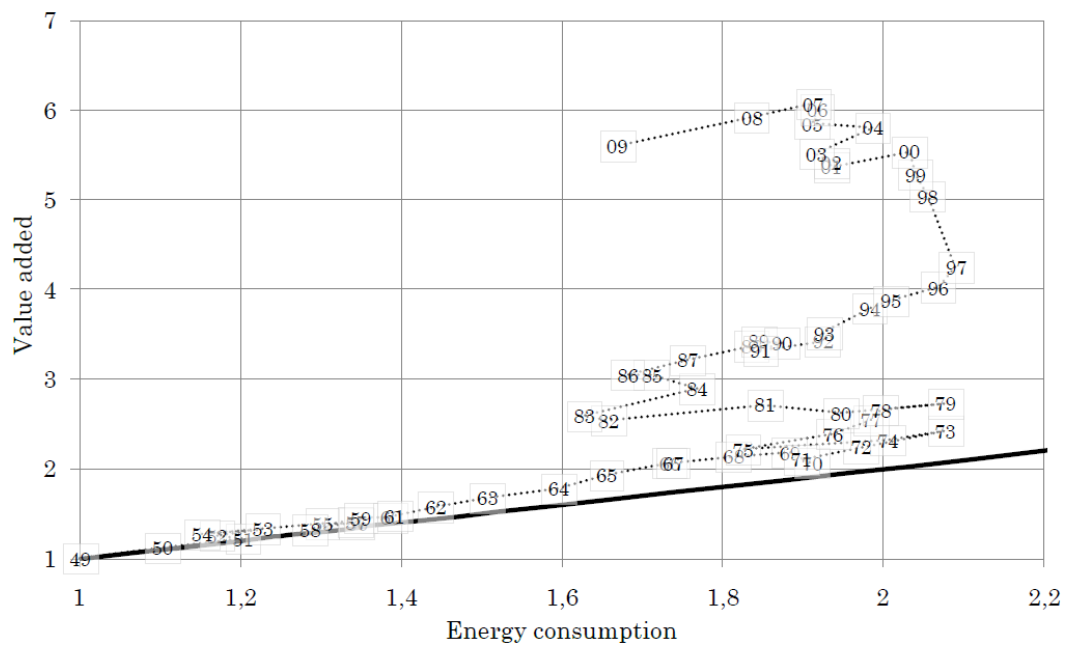

Fig. A.4.1: Development of value added and energy consumption in the industry sector, 1949-2009 (1949=1); solid line represents constant energy efficiency.

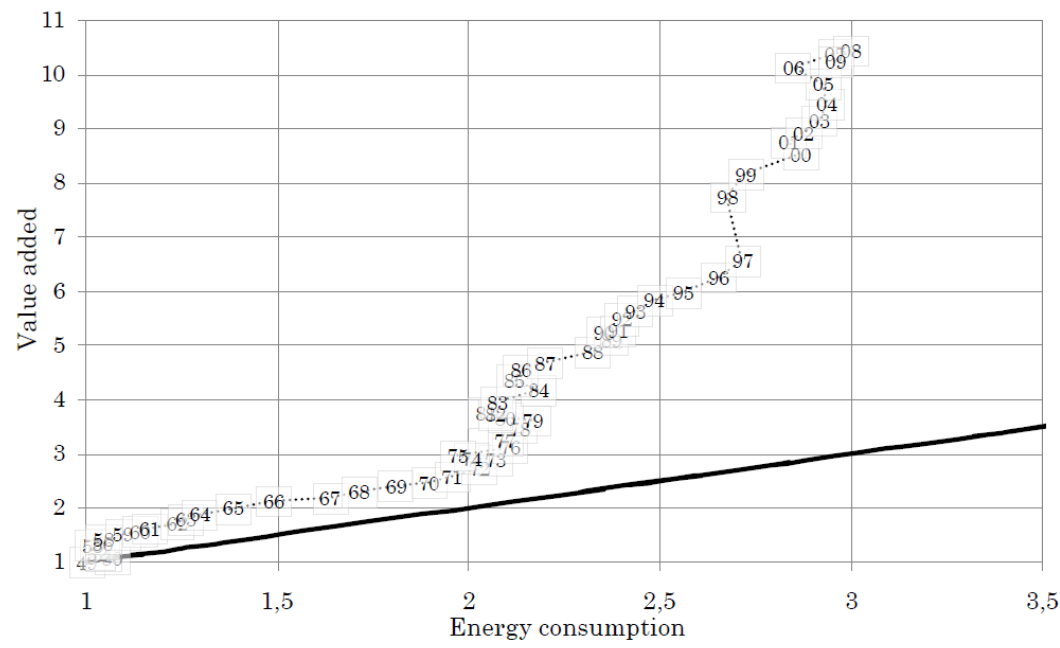

Fig. A.4.2: Development of value added and energy consumption in the commercial sector, 1949-2009 (1949=1); solid line represents constant energy efficiency. 


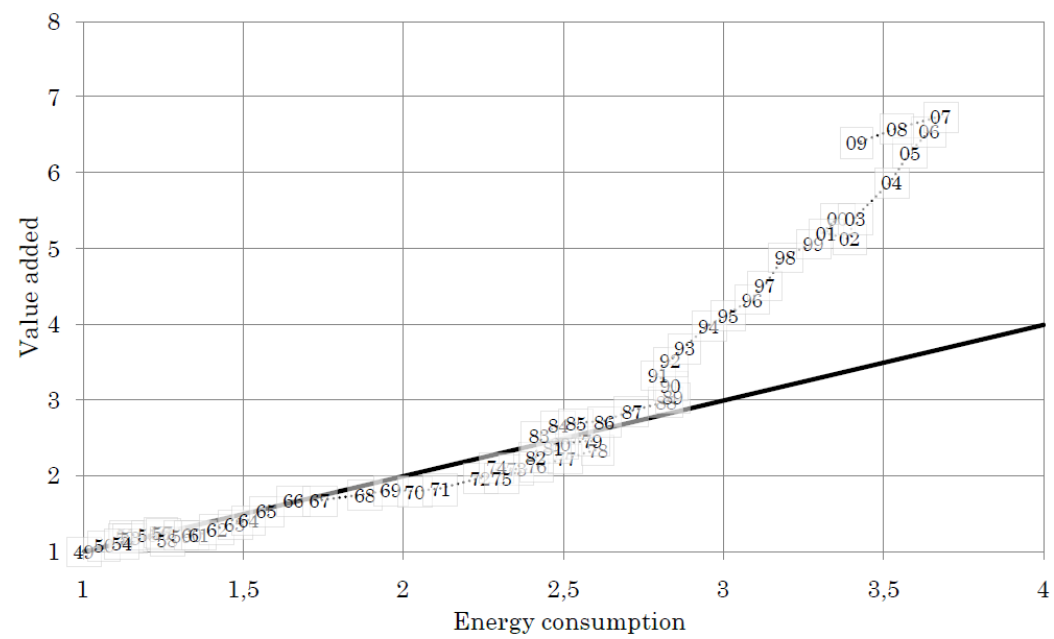

Fig. A.4.3: Development of value added and energy consumption in the transport sector, 1949-2009 (1949=1); solid line represents constant energy efficiency. 


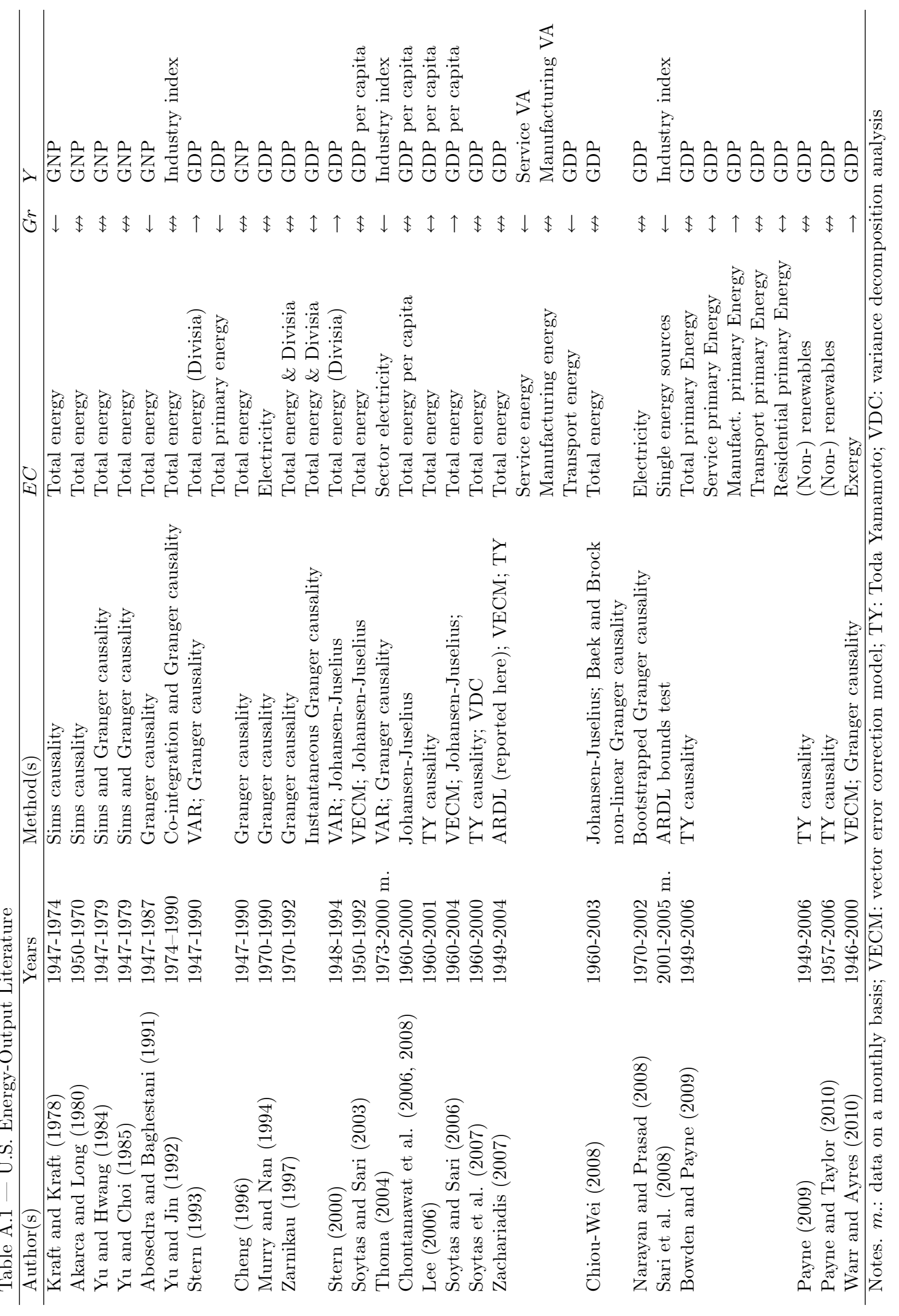


Table A.2 - Lag Order Selection for Unrestricted ECM

\begin{tabular}{llllllllllll}
\hline & & \multicolumn{1}{c}{ Dependent variable } \\
Sector & Model & \multicolumn{1}{c}{$\Delta Y$} & \multicolumn{7}{c}{$\Delta E C$} \\
\hline Total & $\mathrm{A}$ & $(1$ & 3 & - & - & $-)$ & $(3$ & 0 & - & - & $-)$ \\
Industry & $\mathrm{A}$ & $(1$ & 0 & - & - & $-)$ & $(1$ & 0 & - & - & $-)$ \\
& $\mathrm{B}_{1}$ & $(1$ & 0 & 0 & - & $-)$ & $(1$ & 0 & 0 & - & $-)$ \\
& $\mathrm{B}_{2}$ & $(1$ & 0 & - & 0 & $-)$ & $(1$ & 0 & - & 0 & $-)$ \\
& $\mathrm{B} 3$ & $(1$ & 0 & - & - & $0)$ & $(1$ & 0 & 1 & - & $-)$ \\
& $\mathrm{C}_{1}$ & $(1$ & 0 & 0 & 0 & $-)$ & $(1$ & 0 & 1 & 0 & $-)$ \\
& $\mathrm{C}_{2}$ & $(1$ & 0 & 0 & - & $0)$ & $(1$ & 0 & 0 & - & $0)$ \\
& $\mathrm{C}_{3}$ & $(1$ & 0 & - & 0 & $0)$ & $(1$ & 1 & - & 1 & $0)$ \\
Commercial & $\mathrm{D}$ & $(1$ & 0 & 0 & 0 & $0)$ & $(1$ & 0 & 0 & 1 & $0)$ \\
& $\mathrm{A}$ & $(1$ & 0 & - & - & $-)$ & $(1$ & 0 & - & - & $-)$ \\
& $\mathrm{B}_{1}$ & $(1$ & 0 & 0 & - & $-)$ & $(1$ & 0 & 0 & - & $-)$ \\
& $\mathrm{B}_{2}$ & $(1$ & 0 & - & 0 & $-)$ & $(2$ & 0 & - & 2 & $-)$ \\
& $\mathrm{B}_{3}$ & $(1$ & 0 & - & - & $0)$ & $(1$ & 0 & - & - & $0)$ \\
& $\mathrm{C}_{1}$ & $(1$ & 1 & 0 & 0 & $-)$ & $(2$ & 0 & 0 & 2 & $-)$ \\
& $\mathrm{C}_{2}$ & $(1$ & 0 & 0 & - & $0)$ & $(1$ & 0 & 0 & - & $0)$ \\
& $\mathrm{C}_{3}$ & $(1$ & 0 & - & 0 & $0)$ & $(2$ & 0 & - & 2 & $0)$ \\
& $\mathrm{D}_{5}$ & $(1$ & 0 & 0 & 0 & $0)$ & $(2$ & 0 & 0 & 2 & $0)$ \\
Transport & $\mathrm{A}$ & $(1$ & 0 & - & - & $-)$ & $(1$ & 0 & - & - & $-)$ \\
& $\mathrm{B}_{1}$ & $(1$ & 0 & 0 & - & $-)$ & $(1$ & 0 & 0 & - & $-)$ \\
& $\mathrm{B}_{2}$ & $(3$ & 1 & - & 1 & $-)$ & $(1$ & 0 & - & 1 & $-)$ \\
& $\mathrm{C}_{1}$ & $(3$ & 1 & 1 & 0 & $-)$ & $(1$ & 0 & 1 & 0 & $-)$ \\
\hline
\end{tabular}

Note. Lags for $(\triangle Y, \triangle E C, \triangle E P, \triangle C A P, \triangle T R A D E)$ if $\Delta Y$ is the dependent variable; $(\triangle E C, \Delta Y, \Delta E P, \triangle C A P, \triangle T R A D E)$ vice versa.

Table A3 - Lag Order Selection for Restricted ECM

\begin{tabular}{|c|c|c|c|c|c|c|c|c|c|c|}
\hline \multirow{3}{*}{ Sector } & \multirow[b]{2}{*}{ Model } & \multicolumn{9}{|c|}{ Dependent variable } \\
\hline & & \multirow{2}{*}{\multicolumn{3}{|c|}{$\begin{array}{ll} & \Delta Y \\
(10 & 0\end{array}$}} & \multicolumn{5}{|c|}{$\Delta E C$} & \multirow[b]{2}{*}{$-)$} \\
\hline & $\mathrm{A}$ & & & & $-\quad-)$ & $(1$ & 0 & - & - & \\
\hline \multirow[t]{3}{*}{ Industry } & A & $(1$ & 0 & - & $-\quad-)$ & $(1$ & 0 & - & - & $-)$ \\
\hline & $\mathrm{B}_{2}$ & & & - & & (1 & 0 & - & 1 & $-)$ \\
\hline & $\mathrm{B}_{3}$ & $(1$ & 0 & - & 0) & & & - & & \\
\hline \multirow[t]{3}{*}{ Commercial } & A & $(1$ & 0 & - & $-\quad-)$ & $(1$ & 0 & - & - & $-)$ \\
\hline & $\mathrm{B}_{2}$ & $(1$ & 0 & - & $\begin{array}{ll}0 & -)\end{array}$ & $(1$ & 0 & - & 0 & $-)$ \\
\hline & $\mathrm{C}_{3}$ & & & - & & $(2$ & 0 & - & 0 & 0) \\
\hline \multirow[t]{4}{*}{ Transport } & A & $(1$ & 0 & - & $-\quad-)$ & (1 & 0 & - & - & $-)$ \\
\hline & $\mathrm{B}_{1}$ & & & - & & $(1$ & 0 & 0 & - & $-)$ \\
\hline & $\mathrm{B}_{2}$ & & & - & & (1 & 0 & - & 1 & $-)$ \\
\hline & $\mathrm{C}_{1}$ & & & - & & (1 & 0 & 1 & 0 & $-)$ \\
\hline
\end{tabular}




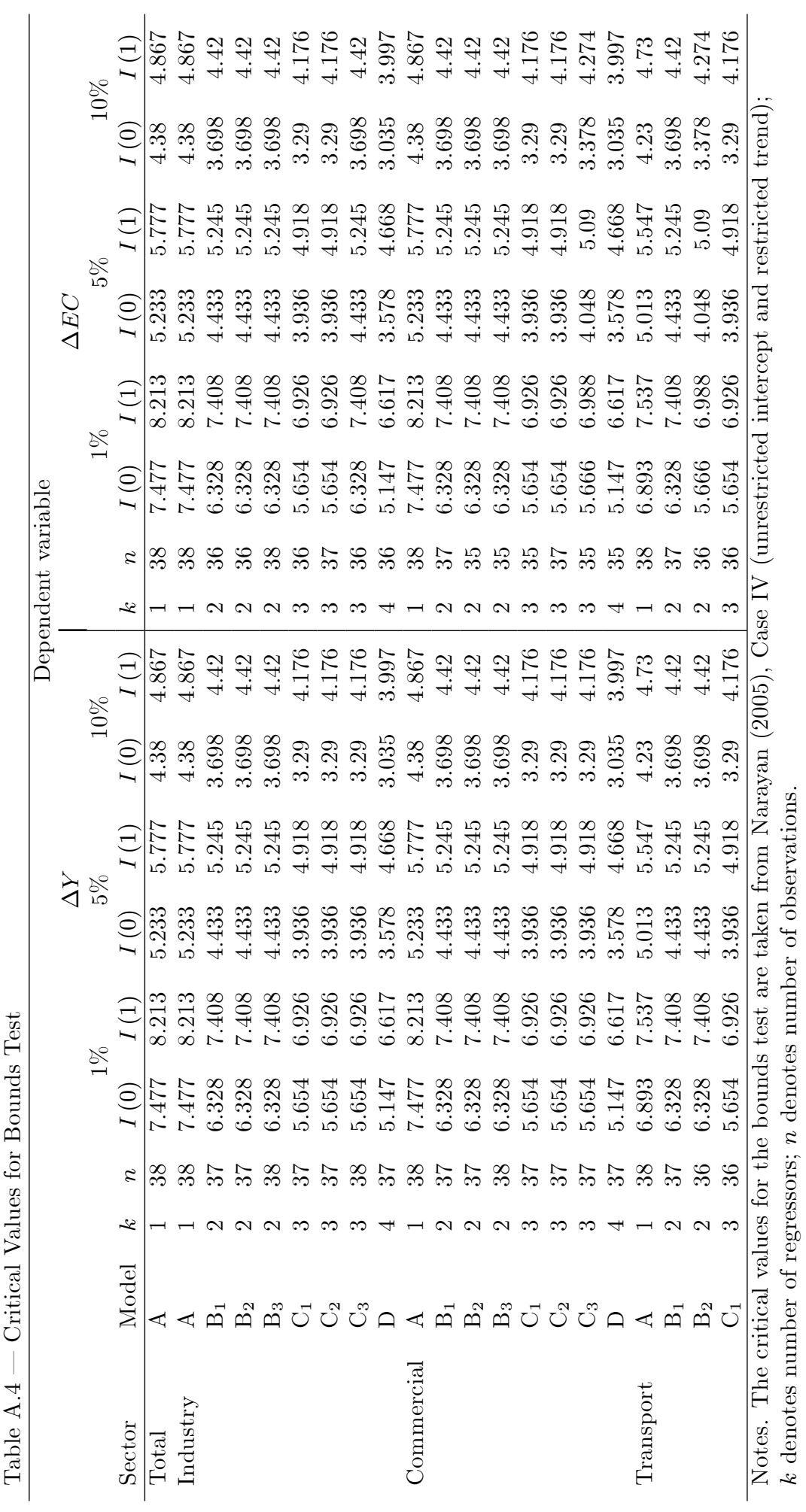

